\title{
Conmemoración estatal y representación escultórica del prócer de la Independencia peruana José Olaya (1823-1953)*
}

\author{
por \\ Rodolfo Monteverde Sotil ${ }^{1}$ \\ Pontificia Universidad Católica del Perú
}

El prócer peruano José Olaya fue un pescador indigena de modesta condición social, diferenciándose por ello de los demás próceres criollos extranjeros, militares y de situaciones económicas sosegadas, que encabezaron la Independencia peruana como José de San Martín y Simón Bolivar. Desde 1823, cuando Olaya fue fusilado por los españoles, cerca de la plaza Mayor de Lima, hasta cuando se cumplieron 130 años de su muerte, el Estado intentó primero homenajearlo con un lienzo (1823) y luego esporádicamente con un monumento público (en 1867, 1923 y 1952). Este texto analiza el contexto social y politico en el cual se propusieron e inauguraron estas esculturas, qué sucedió con ellas y cómo fue representado Olaya.

Palabras Clave: José Olaya; Independencia; prócer; escultura pública; Lima.

Cómo citar este artículo / Citation: Monteverde Sotil, Rodolfo, "Conmemoración estatal y representación escultórica del prócer de la Independencia peruana José Olaya (1823-1953)", Revista de Indias, LXXX/279 (Madrid, 2020): 345-380. https://doi.org/10.3989/ revindias.2020.010.

\section{INTRODUCCIÓN}

Desde 1821 la vida republicana del Perú ha sido un continuo de complejas realidades sociales afectadas por la inestabilidad gubernativa y la corrupción

* Este artículo se desarrolla a partir de la tesis de posgrado del autor, Universidad Nacional Mayor de San Marcos, Unidad de Posgrado de la Facultad de Letras y Ciencias Humanas, maestría en Historia del Arte del Perú y Latinoamérica, sustentada en mayo de 2019.

1 laspuertas48@gmail.com, ORCID iD: https://orcid.org/0000-0001-5804-7774. 
nacional, esta última presente hasta la actualidad ${ }^{2}$, que han provocado que muchas obras públicas no estén libres de malversación de fondos o sean solo propuestas, con meros objetivos personales o políticos, nunca iniciadas o abandonadas al poco tiempo; ya sea durante un mismo periodo presidencial o por el gobierno sucesor debido a desavenencias con el anterior.

Como sucedió en otros países sudamericanos, luego de proclamadas sus independencias de la corona española, en el XIX surgió en el Perú la necesidad de perpetuar a los próceres que participaron en su Emancipación, a través de la escultura pública monumental, de mármol y bronce 3 . En el caso peruano desde los albores de la República los proyectos escultóricos públicos estatales, propuestos para homenajear a los próceres y luego a los héroes de la guerra con Chile (1879-1883), no escaparon de la convulsionada situación social y política nacional, sobre todo entre 1821 y 1900 . En el preludio del $\mathrm{XX}$ los primeros monumentos públicos erigidos en breve tiempo con éxito surgieron de la iniciativa particular pero, de una u otra forma, fueron afectados por la desidia estatal ${ }^{4}$. Por otro lado, la indiferencia estatal y ciudadana

2 Una dura crítica a la corrupción política peruana fue realizada por Flora Tristán en 1834. Tristán, 1971. Alfonso Quiroz escribió un interesante libro sobre la corrupción nacional desde los albores de la Independencia hasta los recientes gobiernos. Quiroz, 2013.

3 Sobre la escultura republicana americana decimonónica consultar Gutiérrez Viñuales y Gutiérrez, 1997 y Gutiérrez Viñuales, 2004.

${ }^{4}$ Por ejemplo, en el XIX nunca fue erigido en Lima el monumento al Día de la Independencia propuesto en 1821 por José de San Martín, ni el de la Batalla de Intermedios, sugerido en 1823 por Hipólito Unanue. Asimismo, muchos proyectos escultóricos esperaron varios años para concretarse debido a la falta de continuidad entre gobiernos, como el monumento a Simón Bolívar, propuesto en 1825 pero inaugurado en 1869 y el de José de San Martín planteado en 1822 pero develado en 1921. En ese lapso en 1904 se convocó a concurso estatal para erigir el monumento a San Martín, pero fue anulado en 1906 porque no se le quiso dar el primer puesto al peruano Carlos Baca Flor debido a las rencillas que la familia del presidente José Pardo tenía con el artista. Un claro ejemplo de que la continuidad de programas y la búsqueda de objetivos comunes logran concretar las iniciativas escultóricas estatales es el monumento dedicado al combate del Dos de Mayo, propuesto al día siguiente del enfrentamiento bélico contra España e inaugurado en un tiempo record, para la época, de ocho años. Luego de la guerra con Chile (1879-1883) surgieron diversos proyectos propuestos por iniciativas particulares que, a diferencia de las intenciones escultóricas estatales, lograron concretarse relativamente rápido: Miguel Grau y los caídos en el combate de Angamos (en 1897 en El Callao, a iniciativa del empresario Peter Bacigalupo), José de San Martín (en 1901 en El Callao, a iniciativa del Comité Patriótico Chalaco), Francisco Bolognesi y los caídos en la batalla de Arica (en 1905 en Lima, a iniciativa de un grupo de colegiales limeños) y José de San Martín (en 1906 en Lima, a iniciativa del empresario Lorenzo Pérez Roca). Sin embargo, muchos de ellos fueron afectados por la desidia estatal. Por ejemplo, en 1906 se inauguró en medio del silencio periodístico y el recelo estatal el monumento a San Martín donado por Lorenzo Pérez Roca a la Municipalidad de Lima, porque el presidente José Pardo había fallado en sus intenciones escultóricas para homenajear al prócer argentino. 
hacia las obras escultóricas erigidas ha sido recurrente en los casi 200 años de República, ya que casi ninguna escultura pública de Lima, y del país en general, se salva del abandono, la falta de protección y la destrucción paulatina, que han sufrido desde sus inauguraciones 5 .

$\mathrm{Al}$ respecto, este artículo se centra en el estudio de las propuestas escultóricas estatales para erigir, en 1867, 1923 y 1952, un monumento público a José Olaya Balandra, prócer de la Independencia fusilado en 1823 en Lima por las tropas españolas. Propuestas que no estuvieron libres de los problemas sociales comentados en líneas superiores, a los cuales se suma la poca valoración, debido al marcado racismo limeño ${ }^{6}$, que Olaya ha recibido de la clase gobernante, en su mayoría criolla, por ser indígena, civil y pobre, características que se contraponen al imaginario nacional memorable del prócer militar, criollo y foráneo que encabezó la Independencia peruana: José de San Martín y Simón Bolívar, y del héroe militar criollo peruano de la guerra con Chile como Francisco Bolognesi y Miguel Grau? Esto también se evidencia cuando, salvo algunos aportes, la bibliografía que nos antecede no se ha centrado en el estudio escultórico de los homenajes estatales a Olaya propuestos en el XIX y el XX, pero sí en los monumentos públicos dedicados a los demás próceres y héroes del Perú ${ }^{8}$.

Años después, en 1921, ante la inminente inauguración del primer monumento estatal a San Martín, por el Centenario de la Independencia, el presidente Augusto B. Leguía mandó trasladar fuera de la ciudad de Lima el donativo de Pérez Roca. José de San Martín 28 de julio de 1821. En Odriozola, 1873, Tomo cuarto: 270. Decreto dado por Unánue el 18 de enero de 1823. En Oviedo, 1861: 184. Vifian, 2016. Monteverde 2010; 2014a; 2014b: 218; 2014c; 2016. Mejía, 2013.

5 Ejemplo de ello podemos mencionar los monumentos limeños al combate del Dos de Mayo (1874) y a Francisco Bolognesi y los Caídos en el Morro de Arica (1905) y el de San Martín en El Callao (1901). Esto también se refleja en varios monumentos decimonónicos y del siglo XX, erigidos en diversas partes del Perú. Por ejemplo, las dos esculturas públicas huamanguinas levantadas, para homenajear a la Batalla de Ayacucho, a partir de la segunda mitad del siglo XIX, en la pampa de la Quinua y la plaza Mayor, las cuales sufrieron la desidia estatal y ciudadana y terminaron colapsando rápidamente. Sobre el contexto en que fue erigido el monumento a Bolognesi ver Monteverde 2017; 2019a.

6 Sobre las marcadas diferencias sociales, económicas y étnicas peruanas de fines del XIX e inicios del XX revisar Burga y Flores Galindo, 1981: 97.

7 Sobre los status de los próceres y héroes del panteón glorioso peruano, podemos mencionar el caso de Andrés Avelino Cáceres, líder de la resistencia peruana durante la guerra con Chile, quién al no morir durante el conflicto bélico, como Grau o Bolognesi, al ser militar y al estar asociado con "la raza indígena" (nació en Ayacucho), no alcanzó el rango de héroe automáticamente. Al respecto leer Millones, 2006.

8 Un importante trabajo de archivo sobre las intenciones estatales para homenajear con una escultura a Olaya es el de Natalia Majluf. La investigadora expone sus datos principalmente en las notas a pie de página de su texto. Majluf, 1994. José Antonio Gamarra Puertas escribió un texto pionero sobre la escultura pública peruana. El autor brinda importante data 
A lo largo del texto nos abocaremos a analizar el contexto social y político en el cual fueron propuestas e inauguradas estas esculturas, qué sucedió con los proyectos con el paso del tiempo y cómo fue representado Olaya. Para realizar nuestro trabajo revisamos diversos documentos legales, diarios y revistas del siglo XIX y XX y publicaciones contemporáneas que, de una u otra manera, hacen alusión a los proyectos escultóricos de Olaya. Asimismo, realizamos registros in situ de varios espacios públicos de Lima y Chorrillos y entrevistas a los vecinos del distrito de Chorrillos, que nos permitieron localizar el busto de Olaya erigido en 1867, sobre el cual la bibliografía consultada no daba ninguna referencia.

Los inicios de La RepúbliCa y La IMAGen de Olaya (1821-1828)

En 1821 José de San Martín proclamó la Independencia peruana y se inició la República. Los primeros años fueron convulsionados por que la corona hispana no había sido derrotada, por ende la Emancipación peruana y americana no estaban aseguradas. En 1823, cuando el ejército español retomó Lima, capital del virreinato del Perú, fue fusilado, el 29 de junio, en un pasaje próximo a la plaza Mayor de la ciudad, José Olaya Balandra, por llevar a nado información secreta entre los patriotas apostados en Lima y los mandos del país refugiados en el puerto del Callao. Después de restaurado el control republicano José Bernardo de Torre Tagle, presidente del Perú, expidió un Decreto Supremo, el 3 de setiembre de 1823, mandando (1) pasar revista por 50 años en la plaza Mayor a Olaya, ascendido a subteniente de la Infantería del Ejército, y luego de ser nombrado vitorear ¡Presente en la mansión de los héroes!, (2) crear un libro en la Municipalidad de Lima para escribir los hechos patrióticos y copiar, en su primera página, el decreto expedido por él para que la fama de Olaya se "trasmita a los siglos", (3) celebrar los 29 de junio en Chorrillos solemnes exequias al prócer, (4) entregar a la madre y hermana el sueldo militar de Olaya y, (5) colocar en la sala de la Municipalidad de Chorrillos un lienzo del pescador con la inscripción: «El patriota José Olaya sirvió con gloria a la patria y honró el lugar de su nacimiento»».

sobre las esculturas de Olaya, pero sus publicaciones adolecen de soporte bibliográfico. Gamarra, 1974; 1996. Los estudios sobre la representación iconográfica de Olaya han estado abocados sobre todo al lienzo de 1828 realizado por Gil de Castro. Al respecto consultar Mondoñedo, 2002. Majluf y Wuffarden, 2015.

9 El decreto expedido por Torre Tagle en 1823 no lo encontramos en el Archivo Digital del Congreso de la República del Perú, tampoco en su colección física de su biblioteca en el 
Aunque en estos homenajes póstumos brilla por su ausencia el escultórico, resultan peculiares ya que están dirigidos a un humilde pescador indígena. Es muy probable que la elevación de Olaya a prócer "muerto" fuera orquestada por las altas esferas del poder político de 1823 y de los demás mandos que gobernaron el Perú durante su convulsionada primera década de vida independiente. Entre otros motivos porque las grandes figuras "vivas" de la Independencia empezaron a perder prestigio nacional. Por ejemplo: José de San Martín se alejó para siempre del Perú envuelto en un halo de fracaso (1822), Bernardo de Torre Tagle terminó sus días confinado en la fortaleza del Real Felipe $(1825)^{10}$, Simón Bolívar dejó el Perú acusado de autoritarismo $(1826)^{11}$ y Antonio José de Sucre sufrió serias consecuencias políticas peruanas debido al sentimiento antibolivariano (1827) ${ }^{12}$.

Así, en medio del caos político, Olaya no representaba amenaza para los jefes militares peruanos, siempre en constante pugna por el mando del país ${ }^{13}$; cuya imagen fue impulsada como referente de prócer local frente a las "opacadas" figuras extranjeras de la Independencia. Por ello no llama la atención que Torre Tagle mandó a inscribir en el lienzo de Olaya «sirvió con gloria a la patria y honró el lugar de su nacimiento». En 1828 el pintor de las principales figuras de la Independencia americana, José Gil de Castro, terminó el lienzo de considerables dimensiones propuesto cinco años atrás ${ }^{14}$ (figura 1).

Aunque no es nuestra intención detallar las características de esta pintura, comentaremos que Olaya fue representado de cuerpo entero, como imagen central que resalta por su volumen, con refinada malla blanca en la cabeza, con traje pulcro, elegante, blanco y luminoso, y con primoroso calzado. Resaltan ciertos atributos estilizados que lo identifican con su procedencia indígena (tonalidad de la piel y rasgos faciales), su oficio de pescador (malla en

centro de Lima. En 1867 Ricardo Palma detalló este decreto y realizó una reseña de Olaya. Palma, 1867: 108-109. También consultar Ramón, 2014: 75-76. Majluf, 2014: 369 y 370.

10 Tauro del Pino, 2001, Tomo 16: 2580.

11 Gosselman, 1967 [1837]: 47.

12 Basadre, 2010: 57. Sobre la imagen de los próceres de la Independencia en la década de 1820 consultar Majluf, 2014: 370.

13 Idem.

14 No existe documentación si el retrato de cuerpo entero de Olaya se colocó en la Municipalidad de Chorrillos. Ricardo Palma mencionó en un artículo publicado en 1867 en La Revista de Buenos Aires, refriéndose a un retrato de Olaya, que en uno de los salones de la Biblioteca Nacional había: «un cuadro, en ese cuadro se ha retratado un indio». Palma, 1867: 103. En julio de 1922 se trasladó al Museo Bolivariano (hoy Museo Nacional de Antropología, Arqueología e Historia del Perú) el cuadro pintado por Gil de Castro, en donde hasta ahora permanece. Sobre los homenajes estatales a Olaya de 1823, y el contexto social y político de esa época consultar Majluf, 2014: 368-373. 
Figura 1. Retrato de José Olaya Realizado POR Gil de Castro en 1828, Óleo sobre tela, $204 \times 137$

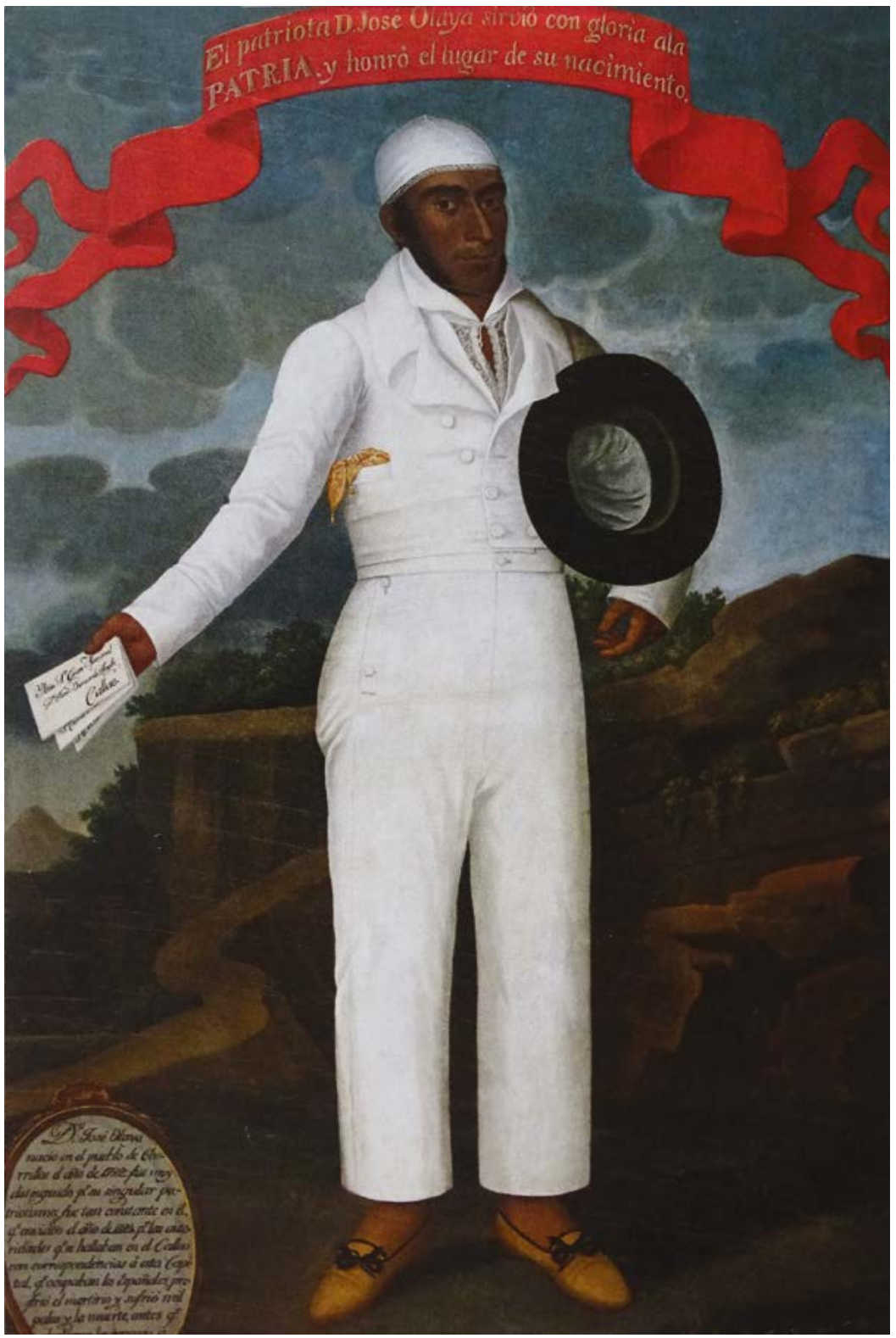

Fuente: Museo Nacional de Arqueología, Antropología e Historia del Perú. Fotografía tomada de Majluf y Wuffarden, 2015: 8. 
la cabeza), su ciudad natal (la caída de "chorrillos" de agua en el escenario natural representado en segundo plano) y su acción patriótica en pro de la Independencia que le costó la vida (las cartas que sostiene en una mano). De esta manera, Gil de Castro representó, a petición estatal, por primera vez la imagen de un indígena, de un hombre de pueblo, como eje central de una pintura, a modo de santo secular de rostro sereno que alcanzó el título de mártir nacional al ofrendar su vida al servicio del país ${ }^{15}$.

No sabemos si todos los homenajes estatales a Olaya, de 1823, llegaron a concretarse, pero lo que sí sabemos es que no incluyeron el escultórico. De haberse propuesto e inaugurado hubiera sido la primera escultura dedicada a un indígena a emplazarse en un espacio público limeño en los albores de la República. Pero debido a la convulsionada década de 1820, por la inestabilidad política, la crisis económica y la tambaleante Independencia que recién se consolidó en 1824, luego de la capitulación del ejército español en Ayacucho, es poco probable que se haya podido encaminar el proyecto como sucedió con los frustrados monumentos al de Día a la Independencia (1821), a José de San Martín (1822), a la Batalla de Intermedios (1823), a la Batalla de Ayacucho (1824) ${ }^{16}$, a la Libertad (1825) ${ }^{17}$ y a Simón Bolívar (1825), que no se concretaron en esa década ni en las dos siguientes, ya que fueron igual de complejas y complicadas para el Perú. Situación que recién comenzó a mejorar a partir de mediados del XIX y que permitió encaminar algunos antiguos proyectos escultóricos como el de Bolívar $(1859)^{18}$ y erigir por primera vez un monumento público a Olaya en la década de 1860 .

\section{Mariano Ignacio Prado y el busto de Olaya en Chorrillos (1867)}

Entre 1823 y 1866, según Gabriel Ramón Joffré, si hubo antecedentes del monumento a Olaya propuesto en 1867 por el presidente Mariano Ignacio Prado (1865-1868), estos pasaron inadvertidos en las guías de la ciudad del siglo XIX ${ }^{19}$. De este periodo resalta que, durante el boom económico alcanzado en la década de 1850 con la venta del guano que financió la im-

15 Mondoñedo, 2002. Majluf y Wuffarden, 2015: 9.

16 En Arosemena, 1974: 113-117.

17 Majluf, 1994: 10, nota 10. Majluf y Wuffarden, 1998: 25, nota 20.

18 Sobre el proyecto estatal del monumento al Día de la Independencia y a San Martín de 1821 y 1822, respectivamente, revisar Monteverde, 2010; 2014; 2014a. Un importante estudio sobre el contexto en que se propuso y se inauguró el monumento a Bolívar en Vifian, 2016.

19 Ramón, 2014: 77, n. 65. 
portación de gran cantidad de esculturas públicas de diversas temáticas ${ }^{20}$, no se encaminara la construcción de un monumento a Olaya. Esta se dio por primera vez cuando Prado mandó erigirlo el 3 de junio de 1867, porque: «nada se ha hecho hasta hoy para premiar tan sublime abnegación, que sea digno del mérito contraído por el expresado ciudadano y del reconocimiento nacional» ${ }^{21}$.

Su iniciativa encaja dentro del contexto victorioso posbélico del combate del Dos de Mayo de 1866, en el cual se derrotó en El Callao a la escuadra española, poniéndose fin a toda intención hispana por intentar recuperar sus antiguos dominios americanos. Esta propuesta estatal evidenció con prontitud: (1) un homenaje escultórico menor en comparación con otros monumentos públicos promovidos, por aquellos años, para conmemorar a otros próceres y enfrentamientos bélicos y (2) una desafortunada improvisación que quiso aprovecharse, con tintes de venganza, de otro proyecto escultórico; a pesar de que se señalaba que el monumento a Olaya era «necesario [para] perpetuar la memoria de los hechos heroicos realizados en la guerra de la independencia, no solo para que sirvan de ejemplo y de estímulo a las generaciones futuras, sino también para dar muestra de gratitud que la nación debe a los sacrificios de sus hijos» ${ }^{22}$.

Sobre el primer punto, el proyecto escultórico no fue sometido a concurso público para elegir un escultor, ni fue realizado en Europa como sí se había hecho en Italia con los monumentos de gran formato de Simón Bolívar, inaugurado en 1859, y de Cristóbal Colón, develado en 1860. Además, en 1866 se había empezado a gestionar en Francia un apoteósico monumento al Combate del Dos de Mayo, inaugurado ocho años después. El monumento a Olaya desde un inicio se propuso como busto, así quedó establecido en el decreto de $1867^{23}$. Esta elección se debería a que el boom económico del guano había decaído notablemente y que el combate del Dos de Mayo había afectado el erario nacional, por ello hubiera sido complejo costear otra escultura monumental en Europa. Esto también se evidencia en el material que fue elegido para realizar el busto, el bronce, ya que se aprovechó una fundición estatal, no especializada en escultura ${ }^{24}$, lo cual evitó mandar a ejecutar el proyecto al "viejo continente".

20 Majluf, 1994.

21 El Peruano, 32 (Lima, 1867, 7 de junio): 164.

22 Idem.

23 Idem.

${ }^{24}$ La factoría pertenecía a la Marina, fue fundada en 1845, se localizaba en El Callao, contaba con una fundición de bronce y hierro y sus servicios no solo se limitaban a la fabri- 
Respecto al segundo punto, a diferencia de otros monumentos contemporáneos, el busto de Olaya se colocaría en una base preexistente en Chorrillos, balneario al sur de Lima, y no en la misma ciudad capital del país, porque, como fue justificado por el Estado, era la ciudad natal del pescador. Dicha base había sido colocada como parte de un proyecto para levantar un monumento al ex presidente Ramón Castilla, muerto pocos días antes (mayo de 1867). La decisión de Prado causó polémica y escándalo. Una dura crítica del escritor Ricardo Palma, en 1867, comentó sobre la demora estatal de cuatro décadas para inaugurar un monumento al "indio" Olaya, la calidad de la obra y las verdaderas intenciones de Prado al proponer el uso de esta base:

Cuarenta y cuatro años han corrido [de 1823 a 1867], cuarenta y cuatro veces el sol ardiente del estío ha iluminado la playa donde el indio mártir soñaba con el sacrificio, aprendiendo en la independencia del mar su propia independencia, y al cabo el gobierno, no la nación, le ha erigido una estatua vergonzante. ¿Se ha cumplido justicia? No, porque ese hecho es demasiado pequeño y va envuelto en una injusticia dolorosa. Olaya es bastante grande, para que necesite su efigie donde la amistad quiso colocar a Castilla. En el campo de la inmortalidad caben todas las glorias; Olaya colocado en ese pedestal es un remordimiento, Castilla despojado de su puesto es un ultraje a la Nación ${ }^{25}$.

La decisión de Prado de usar el pedestal destinado a la escultura de Castilla debe ser entendida en el contexto político del momento. El 17 de mayo de 1866, dos semanas después del combate en El Callao, Castilla regresó al país luego de un largo destierro en Europa. Fue recibido con frialdad y recelo por el presidente. En octubre de ese año, fue arrestado en Iquique por orden presidencial. A pesar de que tenía la salud resquebrajada rechazó al gobierno dictatorial de Prado. Por ello, fue conducido a El Callao y deportado a Chile, donde permaneció vigilado por agentes peruanos. Al año siguiente, a bordo de un navío, partió a Tarapacá en compañía de varios sublevados armados. La muerte le sorprendió el 30 de mayo de 1867 cuando se dirigía a Arica, en donde se habían levantado en contra del régimen pradista ${ }^{26}$. Debido a estas

cación de implementos bélicos sino también a la de todo tipo de maquinarias u otras exigencias que el Estado requería, como por ejemplo la fundición del busto de Olaya. Fue destruida durante la guerra con Chile. Denegri, 1981.

25 Palma, 1867: 109.

26 Castilla antes de fallecer dijo «Señor, un mes más de vida y habré hecho la felicidad de mi Patria». Sobre una bibliografía historiográfica de Castilla consultar la Revista del Instituto Libertador Ramón Castilla, VII / 7, 1867-1967. Lima, Imprenta del Ministerio de Guerra. 
rencillas, no llama la atención que, con tintes de venganza, Prado decretara, cuatro días después de la muerte de Castilla, usar la base del futuro monumento a ser levantado en honor al difunto ex presidente, quien emprendió la remodelación y embellecimiento de Chorrillos y la había denominado como villa en $1856^{27}$.

A fines de junio de 1867, la propuesta escultórica de Salvador Gómez Carrillo de Albornoz fue aceptada por el gobierno, a través de un decreto publicado el 10 de julio en el diario El Peruano ${ }^{28}$. Pese a los reclamos se colocó el busto de Olaya sobre la base del malecón, no sabemos cuándo ${ }^{29}$, pero luego fue sacado y trasladado a la plaza principal de $\mathrm{Chorrillos}^{30}$, probablemente luego de octubre de 1867 cuando Prado fue derrocado y anuladas, por el gobierno entrante simpatizante del ex mandatario Castilla, todas sus disposiciones como presidente ${ }^{31}$. Al poco tiempo el busto de Olaya volvió al malecón porque en la plaza principal de Chorrillos el Estado mandó colocar un busto de Castilla, realizado por Ulderico Tenderini en $1868^{32}$.

27 Crousse e Yrigoyen, s/f: 55-71.

28 Majluf, 1994: 44, n. 81.

${ }^{29}$ Luego de revisar el diario El Comercio de 1867 no encontramos referencia alguna sobre la inauguración del monumento.

30 Majluf, 1994: 44, n. 34.

31 En octubre de 1867 fueron anuladas las resoluciones, decretos y reglamentos expedidos durante el gobierno de Prado, excepto los relacionados a los combates de Abtao y Dos de Mayo. Este decreto fue expedido el 14 de octubre por el segundo vicepresidente constitucional de la República, encargado del Poder Ejecutivo, Pedro Diez Canseco. Al mes siguiente, el 3 de noviembre de 1867, decretó que, entre los honores que el Estado debía rendirle a Ramón Castilla, se le levante un monumento en la Alameda de los Descalzos, en El Rímac, porque «[había muerto] en la provincia de Tarapacá al iniciar la campaña que tenía por objeto reestablecer el imperio de la Constitución y leyes de la República conculcadas por la dictadura [de Prado]».

32 Majluf, 1994: 44, n. 35. No tenemos ninguna otra información de este proyecto pero es probable que el busto de 1868, realizado por Tenderini y mandado a ejecutar por el Estado, esté relacionado al proyecto gubernamental del año anterior. Diez Canseco 1867a y 1867b. Según Natalia Majluf en el malecón y la plaza de Chorrillos existían esculturas. Algunas de ellas fueron sustraídas por el presidente Juan Antonio Pezet (1863-1865); a quien se le acusó de robarlas en 1865. Pezet las mandó ejecutar a Europa para colocarlas en Chorrillos, pero fueron a parar a su rancho privado en dicho balneario. Al respecto revisar Majluf, 1994: 34, n. 44. Además, en 1822 el Congreso le entregó a San Martín, antes de retirarse del Perú, el Estandarte de Pizarro. El testamento del prócer argentino indicaba que debía volver al país. Llegó durante el mandato de Pezet. Durante el caos estatal acarreado por la revuelta de Mariano Ignacio Prado, en 1865, el Estandarte se perdió sospechosamente. Existieron dos estandartes. El otro estaba en la catedral del Cuzco y se le entregó a Sucre para que se lo diera a Bolívar. En la actualidad permanece en la Municipalidad de Caracas. El estandarte de Pizarro se guarda actualmente en el Municipio de Caracas (Lima, 1960, 19 de agosto): 3. 
El busto del prócer ${ }^{33}$, realizado por Gómez Carrillo de Albornoz ${ }^{34}$, siguió el modelo del rostro (rasgos indígenas, pobladas cejas, largas patillas) y, parcialmente, del vestuario (malla de pescador en la cabeza, saco elegante cerrado que deja ver con parcialidad la camisa) de la pintura de Olaya realizada por Gil de Castro en 1828. Pero a diferencia de la pintura decimonónica, donde el rostro de Olaya es sereno, el del busto es adusto ya que tiene el ceño fruncido y la mirada seria puesta en el horizonte (figuras 2 y 3). Este monumento público se convirtió en el segundo en Lima en personificar a un indígena, pero a diferencia del primero, la alegoría de América del monumento a Cristóbal Colón de 1860, el de 1867 representa un bravío prócer peruano que se contrapone a la sumisa alegoría del continente arrodillada a los pies del navegante italiano, quien extasiada y mansa suelta sus flechas y carcaj y extiende una mano para recibir una cruz.

Otra marcada diferencia entre ambos monumentos es el espacio donde fueron emplazados. Mientras que el de 1860 fue levantado en una renovada y moderna alameda del Rímac ${ }^{35}$, próxima a la plaza Mayor de Lima, el

33 En la base del busto se aprecia la firma del escultor (S. Gómez Carrillo), el año en que fue realizado (1867) y el nombre de la factoría en la cual fue ejecutado (Factoría de Bellavista).

34 No hemos encontrado referencia bibliográfica sobre el artista o su producción escultórica. Sobre la escultura peruana republicana del XIX se ha publicado poco. En ese siglo no existía en el Perú un centro de formación escultórica y la estatuaria pública republicana de cánones neoclásicos, de bronce o mármol, de temática civil o militar y de grandes dimensiones, era totalmente novedosa ya que en el Virreinato las esculturas fueron realizadas en madera, eran religiosas, de pequeñas dimensiones y estuvieron destinadas a las iglesias, conventos o viviendas particulares. Casi todas las esculturas públicas y funerarias de mármol inauguradas en el XIX fueron importadas de Europa o ejecutadas en talleres locales de escultores o empresarios extranjeros como Ulderico Tenderini (Italia), Pedro Rosselló (España) y Agostino Marazzani (Italia). Fernando Villegas (2010: 212-213) considera a Gaspar Ricardo Suárez (Ayacucho 18??-1903) el primer escultor peruano formado en Europa. En la República decimonónica también resalta el escultor Luis Medina (Ayacucho) (Gutiérrez Viñuales y Gutiérrez, 1997: 90). La Escuela Nacional de Artes y Oficios fue creada en la década de 1840, veinte años después fue reactivada por poco tiempo debido a problemas políticos y económicos para luego ser afectada por la guerra con Chile (1879-1883). Finalmente, recibió apoyo estatal a inicios del XX y en 1911, al crearse la sección de Bellas Artes, a cargo del italiano Carlo Líbero Valente, se incluyó a la escultura como una de sus ramas de enseñanza. De esta manera surgirían de la Escuela Nacional de Artes y Oficios destacados escultores provincianos que encontraron en la escuela la manera de legitimar su tradición de artesanos (Villegas, 2010: 221): Luis Agurto (Piura), Luis Ccosi (Puno), Artemio Ocaña (Ancash) y Romano Espinoza Cáceda (San Mateo de Huarochirí, Lima); los dos últimos ejecutaron dos proyectos escultóricos para representar a Olaya que analizamos en este texto. Sobre la escultura peruana consultar los trabajos de Castrillón, 1991; Majluf, 1994; Leonardini, 1998 y Villegas, 2010.

35 Comentarios halagadores a esta alameda rimense pueden ser encontrados en los diarios de los viajeros de la segunda mitad del XIX. Un importante estudio sobre esta alameda en Bassi y Zavala, 2014 
Figura 2. Busto de José Olaya, detalles:

(A) VISTA FRONTAL Y (B) NOMBRE DEL ESCULTOR
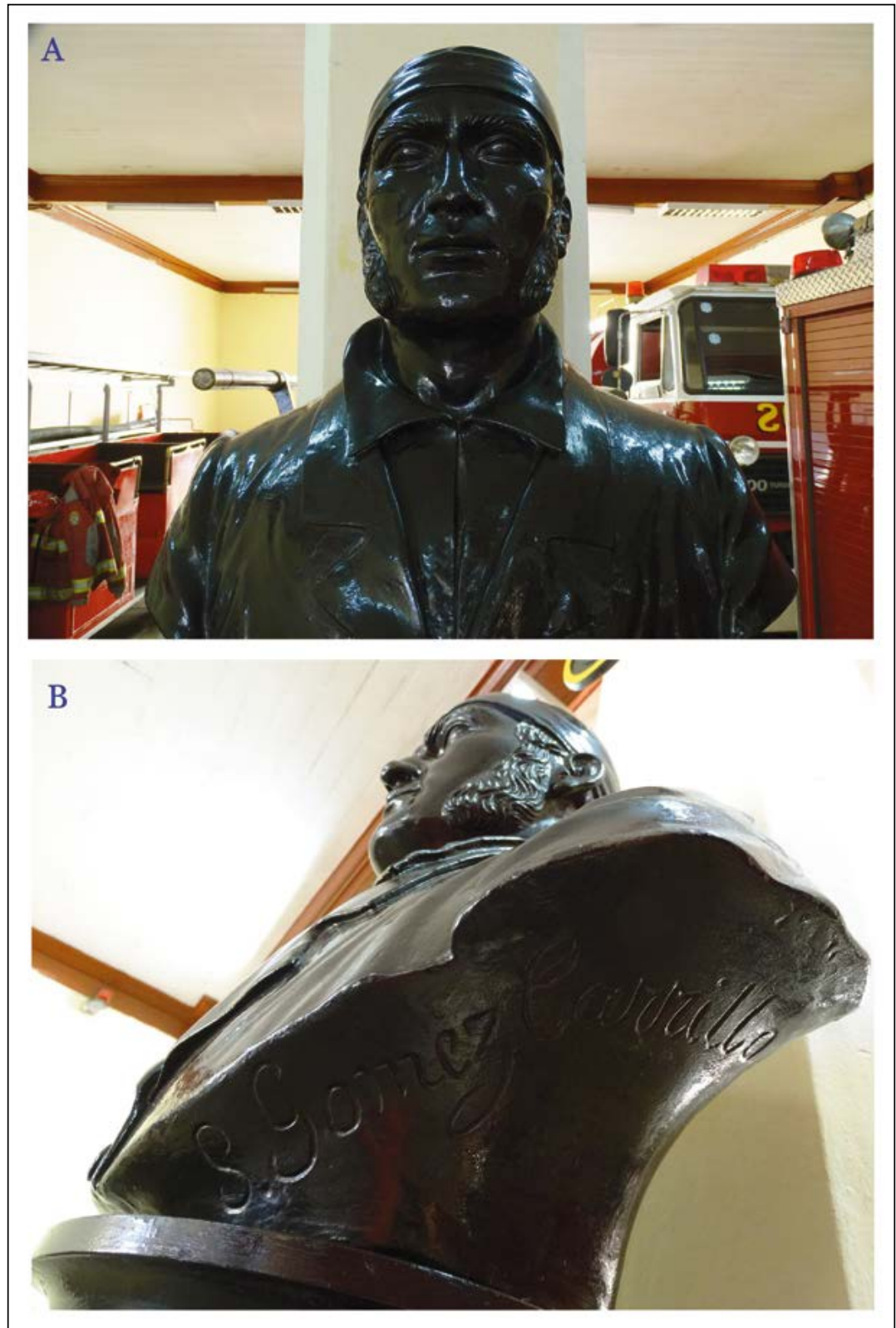

Fuente: fotografías tomadas por Rodolfo Monteverde en 2017.

Revista de Indias, 2020, vol. LXXX, n. ${ }^{\text {o } 279, ~ 345-380, ~ I S S N: ~ 0034-8341 ~}$

https://doi.org/10.3989/revindias.2020.010 
Figura 3. (A) Detalle de la pintura de Olaya Realizada por José Gil de Castro. Busto de José Olaya realizado en 1867; (B) El actual SOPORTE ORTOGONAL PRESENTA DESGASTADO EL NOMBRE DEL PRÓCER Y (C Y D) EN EL LADO DERECHO DEL MISMO SOPORTE SE LEE EL LUGAR DONDE FUE FUNDIDO Y LA FECHA (DEBAJO DEL HOMBRO IZQUIERDO ESTÁ TALLADO EL NOMBRE DEL ESCULTOR: S. GÓMEZ CARRILLO)

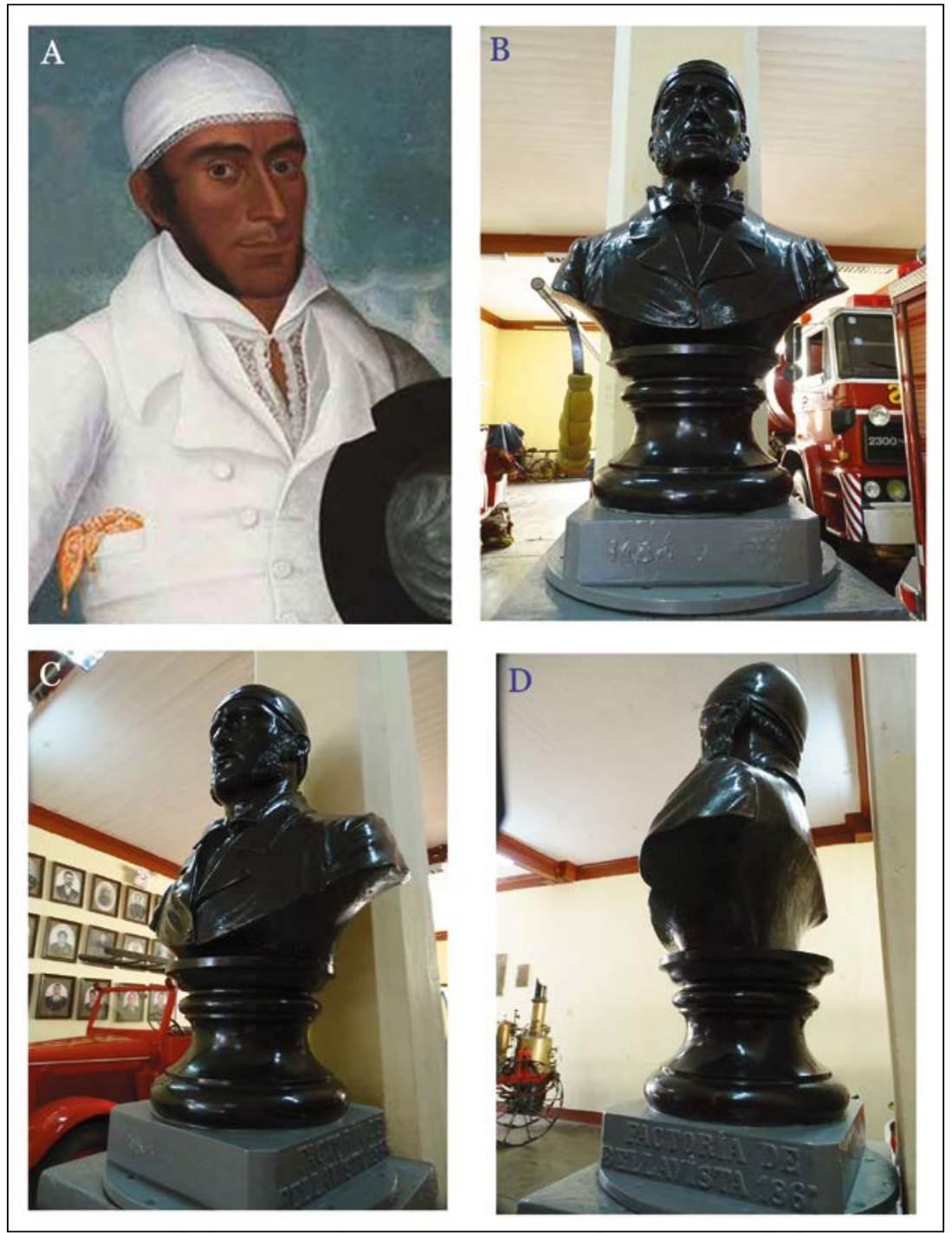

Fuente: (A) Majluf y Wuffarden, 2015. Fotografías tomadas por Rodolfo Monteverde en 2017. 
busto de Olaya fue colocado en Chorrillos, alejado del antiguo casco urbano virreinal, porque, según el documento estatal, era el correcto por ser su lugar de nacimiento. Más allá de esta justificación, y de ser Chorrillos un exclusivo balneario, encontramos poco probable que, a pesar de que era un prócer nacional, el busto de Olaya fuera emplazado en algún espacio público de la ciudad de Lima, en, por ejemplo, el pasaje próximo a la plaza Mayor donde fue fusilado u otro de relevancia, ya que estos fueron destinados, durante el primer siglo de vida republicana, a contener los monumentos de los principales próceres de la Independencia (Bolívar, San Martín y Sucre), el del combate que selló la Emancipación americana (Dos de Mayo) y el del "descubridor de América" (Colón), este último considerado, por los altos mandos del país, un héroe nacional por haber cruzado las temibles aguas del océano Atlántico para traer la civilización y la religión cristiana a este continente ${ }^{36}$.

\section{La posguerra con Chile (FInes del XIX e inicios del XX)}

La guerra con Chile significó la destrucción de Chorrillos por parte del ejército invasor durante la toma de la capital peruana. Luego de finalizado el conflicto empezó su lenta recuperación ${ }^{37}$. A fines de la década de 1880 se reportó en las sesiones del Concejo edil chorrillano que el busto de Olaya se había guardado en la casa de un regidor hasta que fuera colocado en un lugar mejor; posiblemente debido a la alteración física que había sufrido la villa durante el bombardeo chileno. Además, se mencionó que su pedestal estaba muy dañado y que debía ser cambiado ${ }^{38}$.

$36 \mathrm{Al}$ respecto revisar los discursos pronunciados el día su inauguración. Lima. Inauguración de la estatua de Colón (Lima, 1860, 4 de agosto): s/p.

37 A inicios de 1881, en su toma de la capital peruana, las tropas chilenas incendiaron Chorrillos. Asimismo, fusilaron a 13 bomberos de la Compañía Garibaldi por intentar apagar el fuego que consumía a la villa. La remoción de los escombros y el retiro de los cadáveres de los habitantes de Chorrillos y soldados peruanos duró casi todo el año de 1881. Sesión del lunes 20 de junio, 1881: folio 3. Sesión del martes 21 de junio, 1881: folios 4 y 5. Sesión del jueves 29 de setiembre, 1881: folios 13 y 14. Sesión del viernes 21 de octubre, 1881: folio 15. En Actas del Concejo distrital de Chorrillos. Libro 1 (19 de junio de 1881-12 de diciembre de 1890), Chorrillos. Municipalidad distrital de Chorrillos.

38 Ulderico Tenderini presentó un presupuesto para la ejecución del pedestal. Sesión del jueves 2 de julio, 1885: folio 89 y 90. Sesión del jueves 31 de diciembre, 1885: folio 142-145. Sesión del viernes 7 de enero, 1887: folios 232-233. En Actas del Concejo distrital de Chorrillos. Libro 1 (19 de junio de 1881-12 de diciembre de 1890), Chorrillos. Municipalidad distrital de Chorrillos. 
Figura 4. Plano de Chorrillos de 1900

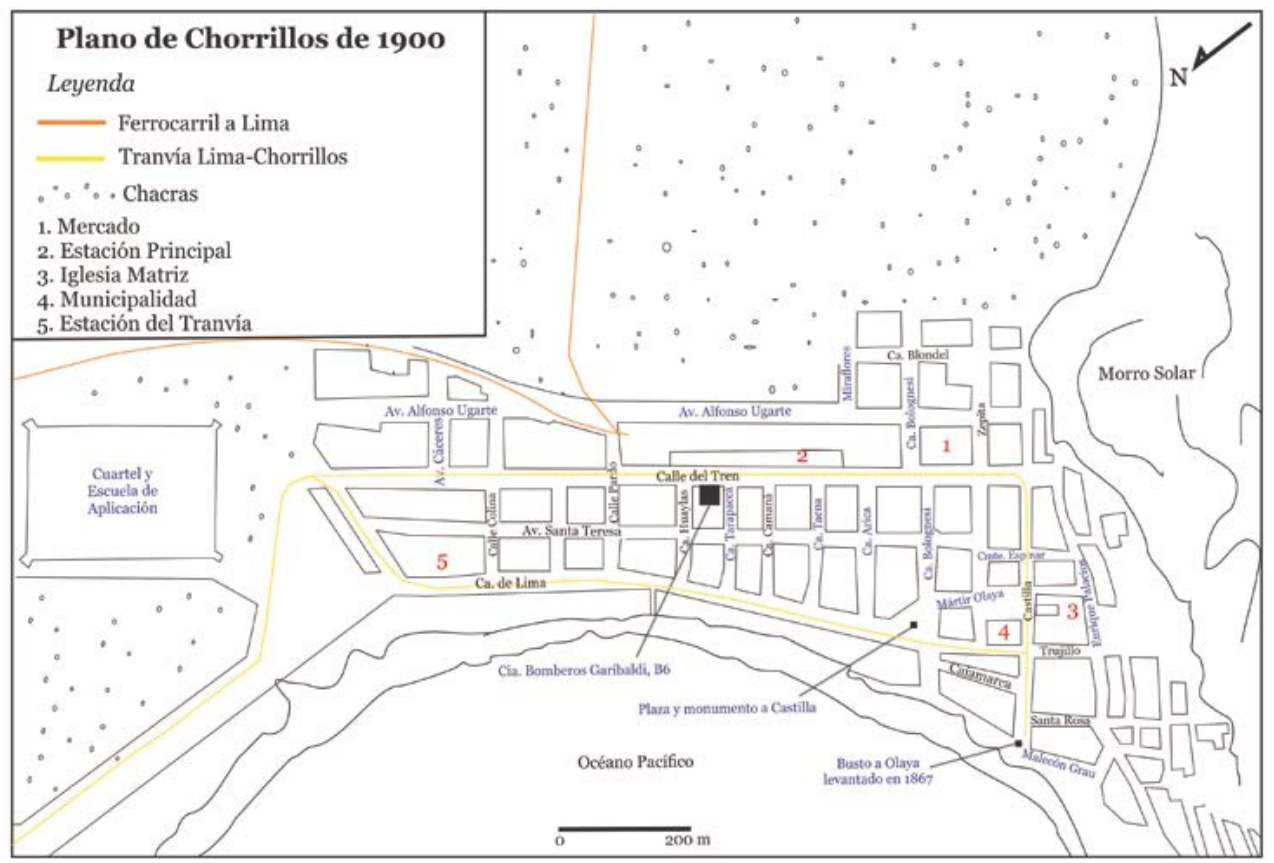

Fuente: redibujado a partir de Cuerpo Técnico de Tasaciones, Plano de Chorrillos de 1900 autorizado por el ingeniero D. Felipe Aranciva. Archivo General de la Nación de Lima, Sede Archivo Colonial, Plano 17, Número antiguo 33.

A inicios de 1887 el busto fue reinaugurado en el malecón ${ }^{39}$. Años más tarde, en un plano de 1900, se aprecia cerca del malecón la localización del busto de Olaya (figura 4). En 1906 la Universidad Nacional de San Marcos donó a la Municipalidad de Chorrillos, que desde 1901 ostentaba el rango de ciudad, el soporte de un inconcluso monumento dedicado a los universitarios sanmarquinos muertos en la guerra con Chile. Como el monumento nunca se concretó, el soporte permaneció vacío por muchos años en la plazoleta limeña de San Carlos (hoy Parque Universitario) ${ }^{40}$. A los pocos años de colocado

39 Sesión del lunes 20 de enero, 1887: folios 233-237. En Actas del Concejo distrital de Chorrillos. Libro 1 (19 de junio de 1881-12 de diciembre de 1890), Chorrillos. Municipalidad distrital de Chorrillos.

40 Sesión del 16 de marzo, 1906: folio 104-106. Sesión del 2 de abril, 1906: folio 110. Sesión del 16 de mayo, 1906: folio 120-121. En Actas del Concejo distrital de Chorrillos. Libro 4 (1 de enero de 1905-30 de diciembre de 1909), Chorrillos. Municipalidad distrital de Chorrillos. San Cristóval, 1999: 89-90. 
el busto de Olaya sobre este pedestal, el conjunto escultórico comenzó a inclinarse debido a la inestabilidad del suelo. Por ello, la Municipalidad de Chorrillos decidió desmantelarlo y guardarlo en su depósito hasta que las obras de mejoramiento de la zona concluyeran $(1909)^{41}$.

\section{La Liga de Defensa NaCional y LA PRIMERA Materialización DE UN HOMENAJE PÚBlico A José OlaYa EN DONDE FUE FUSILADo (1910)}

Después de erigido en Chorrillos en medio de la polémica el busto de José Olaya, hasta fines de la primera década del XX no hubo mayor intento escultórico en Lima para homenajear al prócer. Recién en 1910 se inauguró una placa de bronce, gracias a las gestiones particulares de la Liga de Defensa Nacional, en el callejón de Petateros donde había sido fusilado Olaya (figura 5). Fue inaugurada el 28 de julio, según la misma placa, o al día siguiente, según el programa de fiestas patrias de la Municipalidad de Lima ${ }^{42}$. Al respecto dos puntos importantes: (1) fue la primera vez que se materializó en el escenario de su muerte un homenaje a Olaya, y (2) la placa no fue develada el 29 de junio, como simbólicamente era correcto, sino un mes después durante las celebraciones de la Proclama de la Independencia dada por San Martín en la plaza Mayor de Lima.

Cuando se inauguró esta placa rectangular, sin ornamentación o esculturas en alto relieve, solo con la inscripción «A la memoria de José Olaya mártir del patriotismo ejecutado en este sitio el 29 de junio de 1823 La Liga de Defensa Nacional 28 de julio de $1910 »^{43}$, el pasaje Petateros poseía un deplorable estado. Recién al año siguiente, a iniciativa del Municipio, muchas de las viviendas y negocios que funcionaban en él fueron expropiados y demolidos, en pro de la higiene y ornato de la ciudad ya que «el callejón de Petateros... [era] un feo verrugón de uno de nuestros portales [que se] está cayendo pedazo a pedazo». Esta cruda descripción, publicada en la revista Variedades ${ }^{44}$, revela (1) la ausencia de cuidado a este simbólico espacio urbano donde Olaya falleció por el Perú y (2) la falta de proyección estatal para homenajear al prócer bautizando el remodelado pasaje con su apellido o erigiéndole en él un monumento.

41 Sesión del 14 y 22 de julio, 8 y 11 de agosto, 1909: folios 344 y 348. En Actas del Concejo distrital de Chorrillos. Libro 4 (1 de enero de 1905-30 de diciembre de 1909), Chorrillos. Municipalidad distrital de Chorrillos.

42 Concejo provincial. Sesión del viernes 15 de julio de 1910. Presidida por el señor alcalde don Guillermo Billinghurst, 1910. En Actas de sesiones. Libro 01 (1910-1913), Lima, Municipalidad Metropolitana de Lima.

43 En el extremo inferior izquierdo de la placa se lee «Fund. Piedra Liza».

44 La demolición de Petateros, 180 (Lima, 1911, 12 de agosto): 978. 
Figura 5. Placa limeña de 1910 dedicada a la memoria de José Olaya, colocada en el pasaje Petateros, hoy Olaya

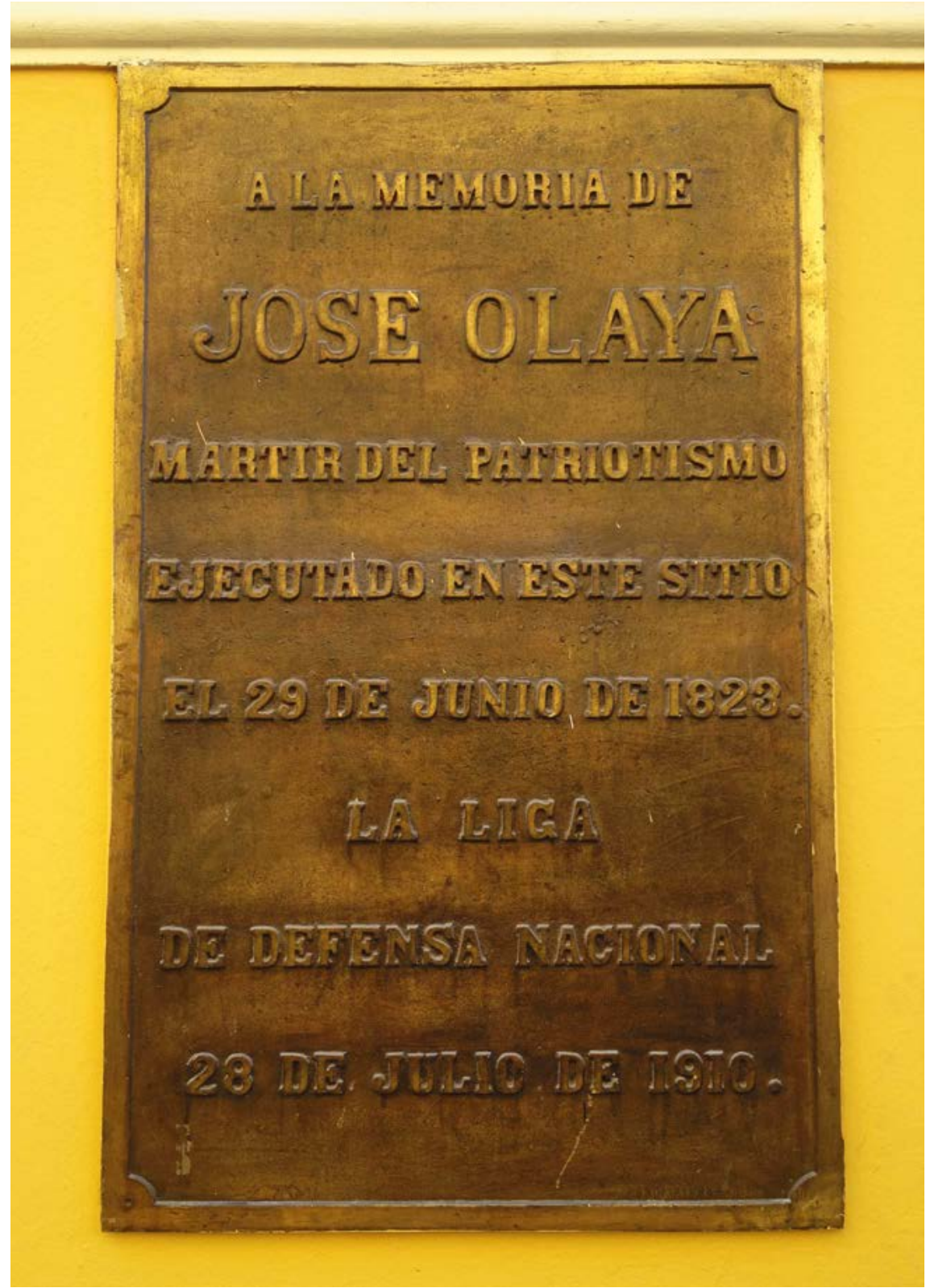

Fuente: Fotografía tomada por Ernesto Monteverde PA, 2017. 
En 1914 el presidente Óscar R. Benavides (1914-1915) propuso, sin éxito, inaugurar en este pasaje el monumento a San Martín, que Mariano Benlliure estaba ejecutando en España por encargo peruano ${ }^{45}$. Esta decisión demuestra que en la agenda estatal no rondaba la idea de alzarle un monumento a Olaya ni rebautizar este pasaje con el nombre del prócer nacional. Con esta intención presidencial solo se estaba alterando el recuerdo de dos espacios de Lima ya que San Martín proclamó la Independencia en la plaza Mayor y no en el pasaje donde había muerto Olaya.

Tres años después, el presidente de la Unión de Labor Nacionalista, el señor Aljovín ${ }^{46}$, le pidió al alcalde de Lima, el 17 de julio de 1917, renombrar el pasaje Petateros como Olaya, a razón de que ahí se pensaba levantarle, según él, un monumento. No sabemos si este proyecto surgió de una iniciativa particular o estatal, pero no llamaría la atención que un grupo de trabajadores de corte nacionalista impulsaran la erección de un monumento a Olaya, pescador indígena, prócer de la Independencia peruana. El Municipio aceptó el pedido el 31 de agosto de ese año ${ }^{47}$, pero seis años más tarde, cuando se celebró el centenario del sacrificio de Olaya, las actividades estatales protocolares se centraron en el balneario de Chorrillos, mientras que en la ciudad de Lima no se colocó la primera piedra del monumento que mencionó Aljovín. De esta manera para 1923, la ciudad capital solo contaba con un pasaje Olaya y una modesta placa que homenajeaba al prócer, a la cual la Municipalidad de Lima colocó una corona de flores; la mayor ofrenda oficial de ese aniversario ${ }^{48}$.

\section{Augusto B. Leguía y el Centenario de la muerte de Olaya (1923)}

Luego de que se retiró del malecón de Chorrillos el monumento a Olaya, en 1909, por el hundimiento del suelo, debido a problemas de filtraciones de agua, permaneció varios años en el depósito edil chorrillano. A pesar de que se hizo un presupuesto para reinstalarlo ${ }^{49}$ esté nunca se ejecutó, ya que en

45 Mejía, 2013: 61-62.

46 Aljovín, 1917. El documento que hemos consultado no tiene tipiado el nombre completo del remitente. En la firma solo es legible el apellido (Aljovín). No hemos encontrado mayor información sobre el señor Aljovín o sobre la Unión de Labor Nacionalista.

$47 \mathrm{La}$ respuesta edil fue tipiada al reverso de la carta del señor Aljovín. Aljovín, 1917.

48 El centenario de Olaya, 164 (Lima, 1923, 6 de julio): s/p.

49 Sesión del 13 y 15 de octubre, 1909: folios 361 y 365. En Actas del Concejo distrital de Chorrillos. Libro 4 (1 de enero de 1905-30 de diciembre de 1909), Chorrillos. Municipalidad distrital de Chorrillos. 
1914 el ciudadano Alejandro von der Heyde ${ }^{50}$ ofreció costear la obra, a colocarse ahora en la plaza Olaya que la Municipalidad chorrillana estaba construyendo ${ }^{51}$. Se tenía planeado inaugurarla en 1918 pero demoras en su trazado lo impidieron. Al año siguiente el recién estrenado gobierno de Augusto B. Leguía (1919-1930) ordenó al Ministerio de fomento concluir la plaza y le propuso levantar en ella un nuevo monumento al pescador con miras a las celebraciones del centenario de la muerte de Olaya $(1923)^{52}$. De esta manera el busto decimonónico a Olaya retornó al malecón y no fue colocado en la plaza que se estaba creando.

Recién el 23 de abril de 1923, dos meses antes del centenario, Leguía promulgó un decreto ordenando levantar el monumento a Olaya en Chorri$1 \operatorname{los}^{53}$. Debido al escaso tiempo no pudo ser inaugurado en junio de ese año. Luego de un concurso público de dos meses, la decisión del Comité pro monumento se inclinó por el proyecto del escultor peruano Artemio Ocaña ${ }^{54}$. A fines de junio de 1923, se publicó en las revistas Variedades ${ }^{55}$ y Mundial ${ }^{56}$ la maqueta realizada por el artista. En dichas notas se resaltó el heroísmo de Olaya, su condición económica, social y su procedencia étnica, a modo de asombro por la triada sui generis: indígena-pescador humilde-prócer.

A diferencia de la representación inmaculada y estilizada que José Gil de Castro realizó de Olaya, Artemio Ocaña asoció en 1923 la imagen del prócer

50 No hemos encontrado referencia bibliográfica sobre él

51 Sesión del 24 de enero, 1914: folio 349. Sesión del 2 de junio, 1915: folios 24-25. En Actas del Concejo distrital de Chorrillos. Libro 5 (30 de noviembre de 1911-14 de diciembre de 1914), Chorrillos. Municipalidad distrital de Chorrillos.

52 Sesión del 13 de setiembre, 1916: folio 124. Sesión del 22 de enero, 1917: folio 136. Sesión del 13 de abril, 1917: 149. Sesión del 13 de mayo, 1918: folio 250. Sesión del 11 de enero, 1919: folio 309. Sesión del 30 y 31 de agosto, 1919: folio 339. En Actas del Concejo distrital de Chorrillos. Libro 6 (21 de diciembre de 1914-6 de junio de 1920), Chorrillos. Municipalidad distrital de Chorrillos.

53 Gamarra, 1974: 174. Nuestra búsqueda del decreto ha sido infructuosa ya que no hemos podido encontrarlo.

54 (Santa 1893-Lima 1980). Egresó del Departamento de Bellas Artes de la Escuela Nacional de Artes y Oficios. Ganador de diversos concursos escultóricos. Se perfeccionó en Roma. A su regreso se le confió la jefatura del Departamento de Bellas Artes. Ejecutó importantes encargos estatales del Oncenio como el monumento público a Petit Thouars de 1924. Tauro del Pino, 2001, Tomo 11: 1817-1818.

55 Las grandes efemérides nacionales. Centenario del martirio y muerte de José Olaya-junio de 1823, 800 (Lima, 1923, 30 de junio): s/p. En homenaje a José Olaya, 801 (Lima, 1923, 7 de junio): s/p.

${ }_{56}$ El sacrificio del chorrillano Olaya, 163 (Lima, 1923, 29 de junio): s/p. Las fiestas en homenaje al patriota José Olaya, 164 (Lima, 1923, 6 de julio): s/p. El centenario de Olaya, 164 (Lima, 1923, 6 de julio): s/p. 
con su faena laboral ruda de pescador: con malla para nadar y bucear cubriéndole los cabellos, semidesnudo (solo con pantalón corto), descalzo y sujetando con su mano izquierda el grupo de cartas que transportó entre Lima y El Callao en 1823. Su rostro con marcados rasgos indígenas es adusto, mientras que su cuerpo semidesnudo es marcadamente apolíneo. La figura pedestre de Olaya descansa sobre un pedestal, asentado sobre graderías, en cuya parte frontal hay una cartela y a ambos lados laterales dos fuentes de agua; que servirían de surtidor público (figura 6a).

Figura 6. (A) Maqueta del monumento de José Olaya diseñada por Artemio Ocaña en 1923; (B) Monumento de Olaya inaugurado

EN JUNIO DE 1952 EN EL MALECÓN DE CHORRILLOS, REALIZADO POR ROMANO ESPINOZA CÁCEDA

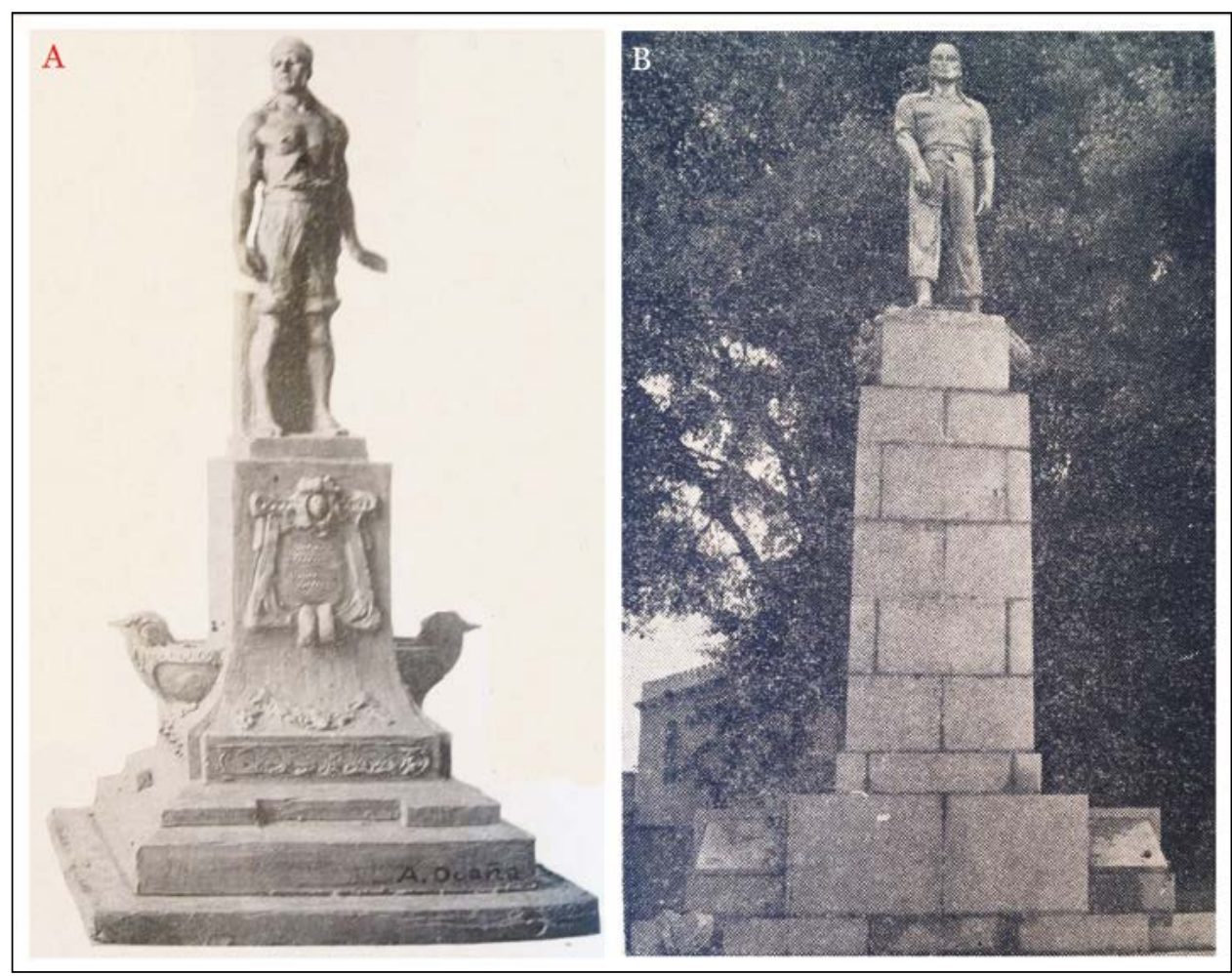

Fuente: (A) imagen tomada de Las grandes efemérides nacionales. Centenario del martirio y muerte de José Olaya-junio de 1823, 800 (Lima, 1923, 30 de junio): s/p. (B) imagen tomada de Hoy serán inaugurados los monumentos al general Miguel Iglesias y al mártir José Olaya (Lima, 29 de junio 1952): 3. 
Figura 7. Busto de José Olaya eRigido en el Malecón DE CHORRILlOS EN 1867: (A) EN 1923 LOS BOMBEROS CHORRILLANOS

LEVANTARON UN ARCO CON SUS ESCALERAS DE INCENDIO

(EN LA PARTE ALTA SE COLOCÓ UN LIENZO DEL PRÓCER

BaSADO EN La PINTURA DE José GIL DE CASTRO);

(B) VISTA DEL BUSTO ILUMINADO LA NOCHE DEL 29 DE JUNIO 1923

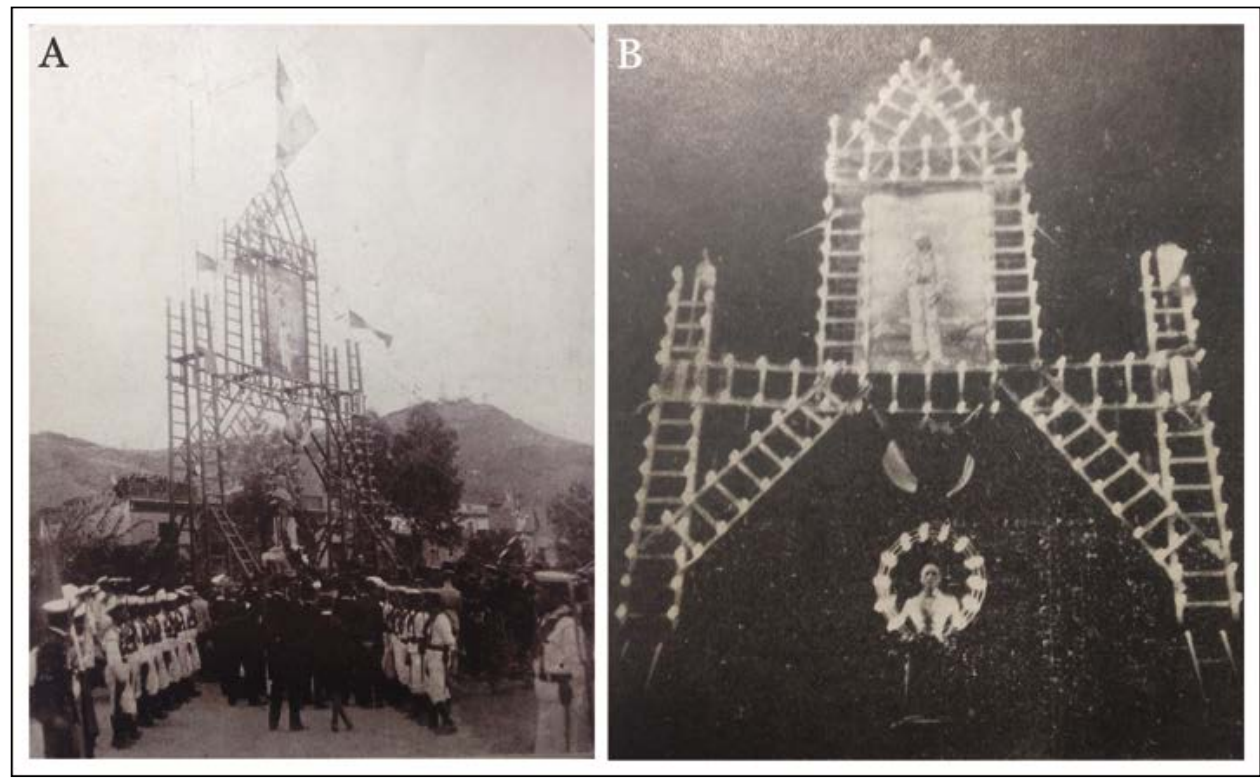

Fuente: (A) imagen tomada de Las fiestas en homenaje al patriota José Olaya, 164 (Lima, 1923, 6 de julio): s/p; (B) imagen tomada de El centenario de Olaya 1923: s/p.

En Chorrillos, durante las ceremonias del centenario de 1923, realizadas el 28, 29 y 30 de junio, la Compañía de Bomberos José Olaya levantó un arco de escaleras, o escalas, en torno al busto del prócer inaugurado en 186757 . En la parte alta y central del arco se colocó una réplica de la pintura realizada por Gil de Castro. Durante las noches el arco y el busto fueron iluminados (figura 7). A la par de estos homenajes Leguía colocó la primera piedra del nuevo monumento a Olaya en Chorrillos (figura 8), en medio de una concu-

57 La Compañía de Bomberos José Olaya, acostumbraba levantar arcos con sus escalas sobre este busto. Por ejemplo, en una foto de 1921, durante la visita de la Embajada Argentina, por las celebraciones del Centenario de la Independencia peruana, se aprecia un arco de escalas alrededor del busto. Romería al monumento Olaya en Chorrillos, 702 (Lima, 1921, 13 de agosto): 1137. 
Figura 8. El presidente Augusto B. Leguía colocando en 1923 LA PRIMERA PIEDRA DEL MONUMENTO A JOSÉ OlAYA EN CHORRILlOS

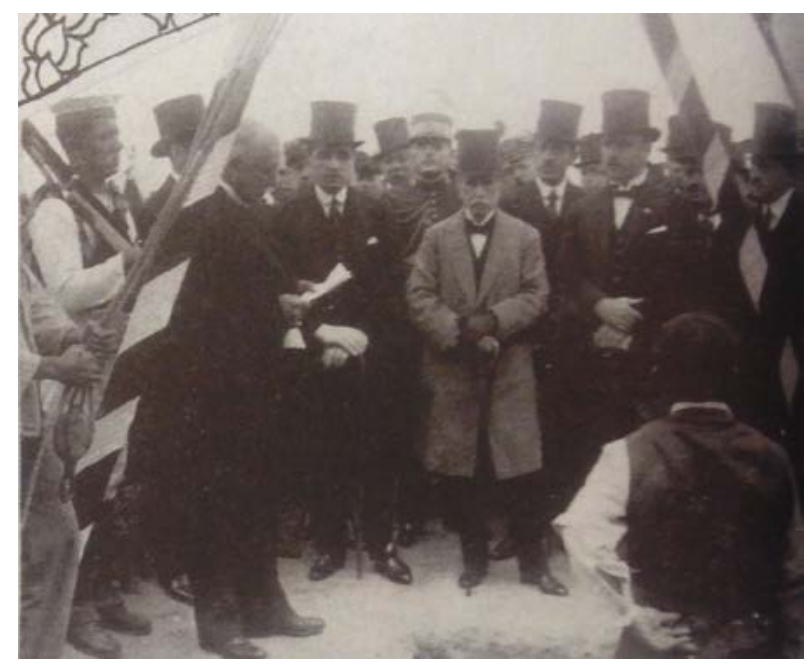

Fuente: imagen tomada de Las fiestas en homenaje al patriota José Olaya, 164 (Lima, 1923, 6 de julio): s/p.

rrida ceremonia pública a la que asistieron diversos representantes de los poderes estatales, el Ejército, la Marina, ciudadanos y escolares ${ }^{58}$.

Sin embargo, aunque en 1923 las revistas señalaron que en breve se inauguraría el monumento, a ser fundido en los talleres de la Escuela Nacional de Artes y Oficios, en la cual Ocaña era profesor ${ }^{59}$, este no fue erigido durante el prolongado gobierno de Leguía, conocido como el Oncenio, caracterizado por la búsqueda de la identidad peruana en el pasado prehispánico, el desarrollo del movimiento artístico del indigenismo y del neoperuano ${ }^{60}$, y por la cuantiosa obra pública que se ejecutó, entre ellos varios monumentos dedicados a los próceres de la Independencia y héroes de la guerra con Chile ${ }^{61}$, cuyas propuestas e inauguraciones estuvieron vinculadas a la delicada situa-

58 Sesión del 29 de junio, 1923: folio 282. En Actas del Concejo distrital de Chorrillos. Libro 7 (14 de julio de 1920-22 de julio de 1923), Chorrillos. Municipalidad distrital de Chorrillos.

59 El sacrificio del chorrillano Olaya, 163 (Lima, 1923, 29 de junio): s/p.

${ }^{60} \mathrm{Al}$ respecto consultar Ramón, 2014.

61 Por ejemplo, los dedicados a los próceres de la Independencia (monumentos a San Martín de 1921 y a Antonio José de Sucre de 1924) y a los héroes de la guerra con Chile (monumento al Soldado desconocido de 1922, a Petit Thouars de 1924 y el Parque de la Reserva de 1929). Monteverde, 2019b. 
ción geopolítica de reclamo diplomático peruano a Chile por la ejecución del plebiscito que decidiría el destino de las ciudades nacionales de Tacna y Arica en posesión chilena desde el término de la guerra ${ }^{62}$. Por ejemplo, en la ceremonia de junio de 1923, cuando se mencionó a los asistentes al evento, en el Libro de Actas de la Municipalidad de Chorrillos, se aludió a este delicado contexto geopolítico: «participó el presidente, ministros, el ejército, marina, escolares, ciudadanía... [son] el arte de defender el territorio en los momentos que se halle en peligro» ${ }^{63}$.

Pero a diferencia de los demás proyectos escultóricos estatales, a pesar de que inicialmente el monumento de Olaya había sido impulsado por el gobierno, este se financiaría con colectas públicas. Por ello, a los pocos días de las celebraciones del centenario se designó, a inicios de julio, a la comisión encargada de ejecutar la plaza Olaya para conformar un comité pro monumento para que reúna el dinero ${ }^{64}$. De esta manera el programa indigenista de Leguía, promotor del neoperuano, no continuó con la propuesta escultórica para homenajear a Olaya. Propuesta solo empleada como mero discurso político no materializada por el gobierno, como así sucedió con diversos programas públicos pro indígenas, que al poco tiempo de ser creados fueron dejados de lado $^{65}$. Luego de derrocado Leguía, en 1930, se inició una dura represalia

62 Monteverde, 2019b.

63 Sesión del 29 de junio, 1923: folio 282. En Actas del Concejo distrital de Chorrillos. Libro 7 (14 de julio de 1920-22 de julio de 1923), Chorrillos. Municipalidad distrital de Chorrillos. Nuestra tesis de maestría en historia del arte (Monteverde 2019b) nos ha permitido conocer las estrategias geopolíticas peruanas en torno a los proyectos escultóricos que se propusieron e inauguraron en la capital peruana. Estas estuvieron influenciadas por el reclamo internacional que el Perú hizo a Chile, principalmente durante el Oncenio, por la ejecución del plebiscito que decidiría el retorno de las ciudades de Tacna y Arica en posesión chilena desde el término de la guerra con este país (1883). Esto se hace evidente, por ejemplo, en las ceremonias de inauguración de los monumentos dedicados a: José de San Martín (1901), Francisco Bolognesi y los Caídos en el Morro de Arica (1905), José de San Martín (1921), El Soldado Desconocido (1922), Antonio José de Sucre (1924), Petit Thouars (1924) y la Libertad (1926). Monteverde, 2019b.

64 Sesión del 8 de julio, 1923: folio 293. En Actas del Concejo distrital de Chorrillos. Libro 7 (14 de julio de 1920-22 de julio de 1923), Chorrillos. Municipalidad distrital de Chorrillos.

65 El Neoperuano, como estilo arquitectónico y decorativo, desarrollado en el Oncenio, comprendió artes gráficas, danza, literatura, música, pintura y teatro. Este estilo fue plasmado en el edificio destinado a albergar piezas arqueológicas peruanas (inaugurado en 1924, hoy Museo de la Cultura Peruana). En el caso de la escultura pública monumental limeña tenemos el pedestal del monumento que sostiene la figura del prócer de la batalla librada en la pampa de Ayacucho, Antonio José de Sucre (inaugurado en 1924) y forma parte del complejo escultórico del monumento al fundador del imperio del Tahuantinsuyo, Manco Cápac (inaugurado en 1926). Asimismo, tenemos las esculturas y ornamentaciones alegóricas del pasado prehispánico emplazadas en el 
contra él y se truncaron varias de sus obras. Por ello resulta inviable que el proyecto escultórico de 1923 fuera continuado por el presidente que lo destituyó, Luis Miguel Sánchez Cerro (1930-1933).

\section{Manuel A. Odría y los 130 aÑos del fusilamiento de Olaya (1952-1953)}

En 1940 un terrible terremoto destruyó Chorrillos. Cuando se emprendió la reconstrucción y remodelación de la ciudad, el malecón, afectado en su totalidad, fue rediseñado y se volvió a levantar en él el busto a Olaya pero con su pedestal incompleto, lo cual le restó esbeltez a la obra ${ }^{66}$. Entre 1948 y 1956 fue presidente del Perú Manuel A. Odría. Su gobierno militar, de corte nacionalista, fue conocido como el Ochenio y se caracterizó por la ejecución de cuantiosas obras públicas sociales ${ }^{67}$. Durante su mandato fue alcalde de Chorrillos Evaristo San Cristóval Palomino (1950-1952), quien lamentó y criticó con dureza las condiciones del monumento a Olaya e impulsó, respaldado por el gobierno central, la erección de otro acorde con las proezas del prócer ${ }^{68}$, pero en vez de continuar con el truncado proyecto de 1923 se emprendió uno nuevo y se le inauguró en 1952.

Parque de la Reserva (inaugurado en 1929). En el caso del monumento al Soldado Desconocido (inaugurado en 1922 en Chorrillos) se representó en el rostro de la escultura del soldado peruano, que luchó en la guerra con Chile, los rasgos faciales indígenas. Vale la pena mencionar que a Leguía le gustaba autonombrarse como Wiracocha. La alegoría simbólica del Perú antiguo, plasmado en el Neoperuano, se contrapone a los proyectos sociales pro indígenas del Oncenio, los cuales al poco tiempo de creados fueron anulados. Por ejemplo, La Sección de Asuntos Indígenas del Ministerio de Fomento, el Comité Pro Derecho Indígena Tahuantinsuyo y el Patronato de la Raza Indígena para 1929 ya no funcionaban. Ramón 2014: 33 y 34, 36. A diferencia de lo sucedido durante el centenario del fusilamiento de José Olaya, en el Oncenio se inauguró en Lima, con motivo de los 100 años de la Proclama de la Independencia, la plaza y monumento a José de San Martín (1921) y, con motivo de los 100 años de la batalla de Ayacucho, la plaza y monumento a Antonio José de Sucre (1924). Ambas celebraciones capitalinas duraron varios días, se recibieron comitivas extranjeras y se desplegó un pomposo programa estatal.

66 Sesión del 25 de mayo, 1940: folios 118-125. En Actas del Concejo distrital de Chorrillos. Libro 13 (1 de enero de 1938-15 de junio de 1943), Chorrillos. Municipalidad distrital de Chorrillos. Crousse e Yrigoyen, s/f: 80. San Cristóval, 1999: 89-90.

${ }^{67}$ Durante su gobierno se realizó un importante plan de construcción vial, se dio a la educación un alto porcentaje del presupuesto nacional, se dotó al Ministerio de Educación de un nuevo edificio, se construyeron numerosos colegios, se inauguró el Hospital del Empleado, el Hospital Naval y Hospital Militar, se erigieron viviendas populares para obreros y empleados públicos, se estrenó el Estadio Nacional, se creó la Central de Asistencia Social y se otorgó el derecho de voto a las mujeres. Tauro del Pino, 2001, Tomo 11: 1822.

68 San Cristóval, 1999: 89-90. 
El 29 de junio de 1952 se develó la escultura de Olaya en medio de un recargado programa de celebraciones organizado por la Municipalidad de Chorrillos. Lo que llama la atención es que las festividades y la inauguración del monumento no se realizaron al año siguiente, en 1953, cuando se cumplían 130 años del fusilamiento de Olaya, y que el eje central de las ceremonias de 1952 no fue la develación del monumento al pescador, ya que también fueron inaugurados ese mismo día, en la cima del morro Solar, un parque y monumento a Miguel Iglesias, militar y ex presidente del Perú, quien en 1883 había firmado el Tratado de Ancón que le puso fin a la guerra con Chile ${ }^{69}$.

El monumento a Olaya fue realizado por el escultor peruano Romano Espinoza Cáceda ${ }^{70}$ (figura 6b). Su obra se diferencia de la de Ocaña, proyectada 29 años atrás, por (1) las características del pedestal construido con bloques cuadrangulares de piedra sin mayor ornamentación en cuya base se colocaron dos placas, y (2) por la escultura pedestre del prócer chorrillano que, a diferencia de Ocaña, lo representó con el torso cubierto y con pantalón largo de trabajo, pero con igual morfología fornida. A raíz de esta inauguración y porque en su ubicación se colocaría un monumento, que nunca se llegó a concretar, dedicado a los bomberos garibaldinos fusilados durante la guerra con Chile ${ }^{71}$, el busto de Olaya fue retirado nuevamente del malecón.

Su destino fue el depósito del Municipio chorrillano, en donde permaneció abandonado y olvidado por un año. Cuando lo encontraron los bomberos de la Compañía José Olaya, B13, estaba cubierto de polvo y hacinado junto con otros objetos. Ante esta luctuosa situación, solicitaron su traslado a la com-

69 Para el 129 aniversario de la muerte de Olaya se programó una serie de conmemoraciones, que empezaron el sábado 28 y continuaron hasta el 29. Además del monumento a Olaya, se inauguró la escultura y parque General Miguel Iglesias en lo alto del Morro Solar, gracias a las gestiones de su sobrino Germán Luna Iglesias. En la actualidad no existe ningún parque en la cima del Morro y la escultura del general está abandonada, además los pocos visitantes no saben a quién representa ya que no tiene ninguna placa. Para mayores detalles sobre las celebraciones estatales del 29 de junio de 1952 consultar Esta noche inician las actuaciones conmemorativas del 129 aniversario del sacrificio de José Olaya (Lima, 1952, 28 de junio): 7. Hoy serán inaugurados los monumentos al general Miguel Iglesias y al mártir José Olaya (Lima, 29 de junio 1952): 3. Las ceremonias y actuaciones conmemorativas del 129 aniversario del sacrificio de José Olaya en Chorrillos (Lima, 1952, 29 de junio): 3 .

70 Romano Espinoza Cáceda (1898-1957) nació en San Mateo de Huarochirí, Lima. Estudió escultura en la Escuela Nacional de Artes y Oficios, en la Escuela Nacional de Bellas Artes y en Europa. Alayza Paz Soldán, 1940.

71 Sesión del 18 de julio, 1952: folio 17. En Actas del Concejo distrital de Chorrillos. Libro 16 (1 de enero de 1952-10 de febrero de 1956), Chorrillos. Municipalidad distrital de Chorrillos. 
Figura 9. ENTREga Protocolar del busto de José Olaya en 1953 a la Compañía de Bomberos José Olaya, B13

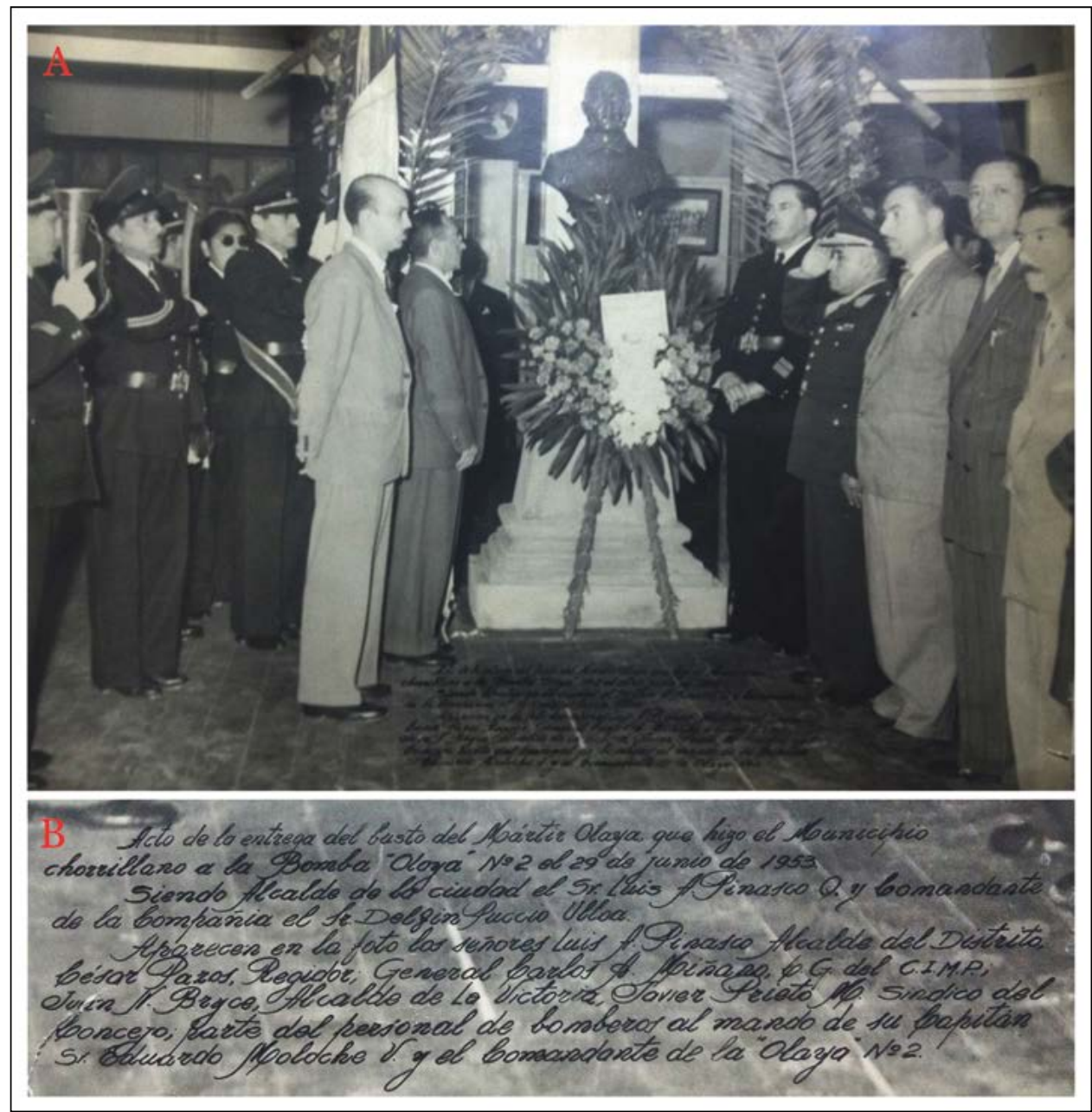

Fuente: fotografía cedida por los efectivos José Morales Bermúdez Saldarriaga y Luis Vargas Rojas de la Compañía B13. 
pañía fundada en 189072. El 29 de junio de 1953, cuando se cumplieron 130 años del sacrificio de Olaya, la Municipalidad de Chorrillos entregó el busto, el cual fue colocado en la sala de máquinas de los bomberos chorrillanos, pero esta vez sobre un pedestal de cemento, en donde hasta la actualidad permanece protegido (figura 9$)^{73}$.

\section{EPÍLOGO}

Los homenajes a Olaya estuvieron presentes en la agenda estatal esporádicamente desde inicios de la república peruana: en 1823, a través del retrato pictórico, cuando aún no estaba consolidada la Independencia, y en 1867 con una propuesta escultórica, luego de ser reafirmada la Emancipación de España con el combate del Dos de Mayo de 1866. Ya en el siglo XX se plantearon dos monumentos a Olaya con motivo del centenario de su muerte (1923), y por los 129 años de su fusilamiento (1952). Las propuestas decimonónicas difieren en que la primera buscó, a través del lienzo, imponer en el panteón de los próceres una figura local frente a los militares criollos extranjeros que lideraron la Independencia peruana, mientras que en la segunda Prado aprovechó la coyuntura nacional victoriosa, luego del combate del Dos de Mayo, para rendirle homenaje al prócer chorrillano y, al mismo tiempo, utilizar su proyecto como venganza en contra del monumento de su "enemigo político" Ramón Castilla. En el siglo XX la representación escultórica de Olaya se justifica no solo por los aniversarios de su muerte sino también por el programa nacionalista del Oncenio y del Ochenio, que encontraron de suma importancia que el prócer pescador, pobre e indígena fuera revalorizado en el imaginario social del país a través de un monumento público en Lima. A diferencia del Ochenio, en el Oncenio la propuesta escultórica no pasó de la colocación de su primera piedra.

Los diferentes contextos y objetivos estatales comentados influenciaron en la representación de Olaya entre 1823 y 1952. Así, desde un Olaya de rostro apacible, cuerpo esbelto y vestido elegante y radiantemente sobresaliendo del lienzo como una incandescente luz para guiar el derrotero de la novel, sacri-

72 Esta información fue recogida en febrero y mayo de 2017 de los efectivos Steven Arce, José Morales Bermúdez Saldarriaga y Luis Vargas Rojas, bomberos de la Compañía José Olaya.

73 En mayo de 2017 José Morales Bermúdez Saldarriaga y Luis Vargas Rojas nos mostraron una fotografía de la entrega del busto de Olaya a los bomberos de B13, la cual reproducimos. La foto lleva una inscripción original en la parte central inferior en donde se describe la entrega del busto y se señala la fecha: 29 de junio de 1953. 
ficada y trastabillante república (lienzo de Gil de Castro), vemos como en el rostro del busto de 1867, luego del victorioso combate frente a los españoles, se imprimen rasgos adustos y bravíos al prócer pero sin dejar de lado la representación del vestuario elegante del lienzo.

Ya en el siglo XX, durante dos gobiernos de facto, autoritarios y nacionalistas, Olaya fue representado escultóricamente con rostro serio y arisco, ataviado con ropa modesta, en plena faena de pescador y mostrando una atlética musculatura. Es decir, con el paso de los años la figura de Olaya fue de una representación sacra, apacible, estilizada y elegante a una más apegada a la realidad laboral de un pescador, pero que a la vez fue idealizada apolíneamente para resaltar su actitud desafiante en pro de la defensa de la Patria debido al diferendo territorial con Chile por la devolución de Tacna y Arica, en el caso de la estrategia geopolítica del Oncenio, y en pro de los derechos laborales de los trabajadores obreros y de valentía nacional que los próceres patrios debían demostrar, en el caso del programa social del gobierno militar del Ochenio $^{74}$.

En 130 años, entre 1823 y 1953, solo dos propuestas escultóricas lograron concretarse en Chorrillos. En 1823 fue complicado invertir en monumentos debido a la convulsionada situación nacional. A mediados del XIX, luego de un periodo de boom económico se pasó a una crisis económica acarreada por el despilfarro del erario nacional y los gastos del combate de 1866, por ello las facilidades de contar con un escultor y factoría nacional hicieron posible la prontitud de la inauguración del modesto busto de 1867. Con el correr de los años este busto descansó sobre diversos soportes los cuales, al mismo tiempo, sufrieron varias alteraciones. Asimismo, su localización no fue de la mano con la adecuación de un espacio público en Chorrillos y cuando se creó la plaza Olaya se propuso colocar en ella otro monumento "más acorde" con el prócer. En el XX el primer proyecto escultórico para rendir homenaje a Olaya fue tomado por el Oncenio. Lo que llama la atención es que no se concretara, ya que el gobierno de Leguía destacó por la cuantiosa inaugura-

74 Al respecto, en la década de 1950, el general Manuel A. Odría mandó cambiar la estatua de Francisco Bolognesi del monumento ejecutado por Agustín Querol e inaugurado en Lima en 1905, porque había sido representado mal herido y desfalleciente. En el imaginario popular su postura semejaba a la de un "ebrio". Por ello se decidió colocar sobre el monumento la escultura de un Bolognesi más solemne y bravío alzando la bandera nacional y su revolver con firmeza y decisión heroica. El 7 de junio (aniversario de la batalla de Arica) de 1951 el Poder Ejecutivo decretó convocar a concurso público para elegir a un escultor. Resultó ganador Artemio Ocaña. Zenón Noriega, general presidente del Concejo de Ministro y ministro de Guerra, en una carta escrita al alcalde Lima, señaló que los principales diarios limeños apoyaban el cambio. Noriega, 1951. 
Figura 10. El busto de José Olaya: (A) Foto Publicada en 1923

A RAZÓN DEL CENTENARIO DE LA MUERTE DEL PESCADOR, (B) EL BUSTO en la Compañía de Bomberos José Olaya de Chorrillos, B13

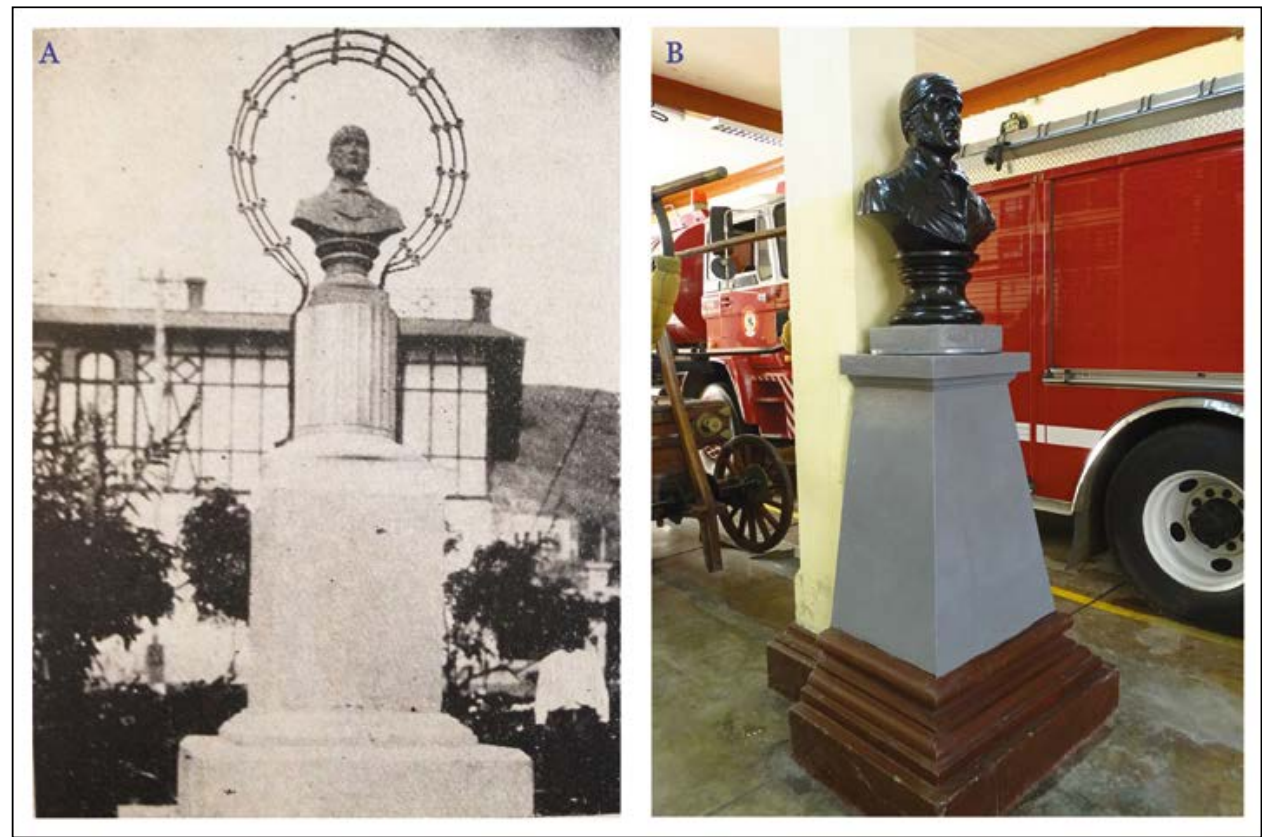

Fuente: (A) tomado de Las grandes efemérides nacionales. Centenario del martirio y muerte de José Olaya-junio de 1823, 800 (Lima, 1923, 30 de junio): s/p; (B) fotografía tomada por Rodolfo Monteverde en 2017.

ción de esculturas públicas, además que ya se había seleccionado el proyecto de un escultor nacional, Artemio Ocaña, director de la Escuela de Arte y Oficios donde existía una fundición.

A mediados del siglo XX se seleccionó a otro escultor peruano, Romano Espinoza Cáceda, quien encaminó su proyecto siguiendo a grandes rasgos las características plásticas del monumento propuesto en el Oncenio. Su obra actualmente ya no posee las placas originales colocadas en la base del pedestal y el piso que lo rodea está en muy mal estado de conservación. La inauguración de este monumento y la fallida propuesta de la erección de un monumento en honor a los bomberos fusilados por las tropas chilenas, significó que el busto de Olaya, de 1867, fuera retirado del espacio público chorrillano, como varias veces había sucedido, y abandonado a su suerte hasta 1953 en que fue reinaugurado en otro lugar, igualmente como varias veces había su- 
cedido, pero esta vez lejos del espacio público, ya que fue colocado en los interiores del cuartel de Bomberos B13, sobre un soporte totalmente distinto a los muchos que tuvo desde que fue inaugurado (figura 10).

Los artistas peruanos que representaron a José Olaya (1) se valieron de su vasta producción artística para poder ascender socialmente y (2) su selección estatal para ejecutar las obras se debió a su trayectoria e importancia en el ámbito artístico peruano. Sobre el primer punto, José Gil de Castro, nacido en 1785, fue un pintor mulato limeño formado, posiblemente, en talleres particulares de pintores limeños tardíos del Virreinato, quien a partir de 1816 adquirió mayor relevancia profesional con la representación pictórica de los principales próceres de la Independencia sudamericana ${ }^{75}$. Respecto al escultor decimonónico Salvador Gómez Carrillo de Albornoz no sabemos nada, pero por el contexto del XIX es posible que se trate de un artista, nacional o foráneo, formado en Europa y radicado en el Perú. En el caso de Artemio Ocaña y Romano Espinoza Cáceda, ambos forman parte de un grupo importante de artistas migrantes, nacidos a fines del XIX, quienes en las primeras décadas del XX encontraron, en la capital del Perú, en la Escuela Nacional de Artes y Oficios, la posibilidad de desarrollarse profesionalmente a través del ejercicio escultórico y así obtener importantes encargos estatales y particulares. Respecto al segundo punto, cuando fueron elegidos para representar al prócer Olaya, ya eran destacados artistas, con importantes obras y ostentaban el reconocimiento estatal y social. Por ejemplo, a partir de 1825 , cuando Gil de Castro radicaba en Lima fue reconocido por el gobierno como primer Retratista de Cámara del Perú ${ }^{76}$. Tres años después elaboró el retrato mandado por Torre Tagle. Ya en el XX, durante el Oncenio, Ocaña fue un recurrente ejecutor de esculturas estatales y particulares. Periodo en el cual su proyecto escultórico de Olaya fue seleccionado por el gobierno de Leguía. Años después, en la década de 1950 un maduro y experimentado Romano Espinoza realizó el primer monumento pedestre de Olaya.

Durante todo este tiempo, entre 1823 y 1923, la ciudad de Lima no contó con un monumento a Olaya, tan solo con una placa colocada, en 1910, en el pasaje Petateros, donde fue fusilado. Los reclamos ciudadanos estuvieron siempre presentes desde las primeras décadas del XX y continuaron por muchos años. Por ejemplo, en 1964 el sobrino bisnieto de José Olaya pidió que se erigiera en este pasaje un busto o monumento al prócer, para que no se olviden de él, ya que en junio de todos los años solo se le rinde homenaje en

\footnotetext{
75 Mondoñedo, 2002

76 Idem.
} 
Chorrillos ${ }^{77}$. Recién en 1985 se levantó un monumento a Olaya en este pasaje, que hasta la actualidad sobrevive in situ. Pero este y los monumentos a Olaya que posteriormente se propondrían e inaugurarían en diversos sitios del Perú merecen ser analizados con mayor detenimiento en un artículo independiente ya que están insertos en contextos sociales, políticos y culturales diversos y complejos acarreados desde mediados del XX, que incluyen, por ejemplo, las migraciones masivas a la capital peruana, el gobierno nacionalista revolucionario de las Fuerzas Armadas y el surgimiento del movimiento terrorista de Sendero Luminoso.

\section{AgRAdECIMIENTOS}

A los efectivos de la Compañía de Bomberos José Olaya de Chorrillos: Steven Arce, José Morales Bermúdez Saldarriaga y Luis Vargas Rojas. A Arcadio Encarnación Huisa, encargado del Archivo Central de la Municipalidad de Chorrillos, a Mario Sonco Gordillo, funcionario de la Biblioteca Municipal de Chorrillos y a los trabajadores de la Biblioteca Municipal de San Isidro. A Eduardo Vásquez por compartir información sobre monumentos chorrillanos. A Álvaro Monteverde Sotil por su compañía durante el recorrido que realizamos en Chorrillos en el verano de 2017. A mi padre por llevarnos hace muchos años a mis hermanos y a mí a recorrer los espacios públicos de Chorrillos. A Ernesto PA. A Nanda Leonardini por su ayuda y consejos invalorables. A las importantes observaciones de los evaluadores de esta revista.

\section{BIBLIOGRAFÍA}

Alayza Paz Soldán, Luis, Romano Espinoza Cáceda. Nuestro escultor vernáculo, Lima, Editorial Mercurio, 1940.

Aljovín, "Carta al señor alcalde del Consejo Provincial de Lima". En Honorable consejo Provincial de Lima. Sección Archivo y Mesa de Parte. Archivado Casilla, 1917, $N^{\circ}$ 22, Expediente $N^{\circ}$ 574, Folio $N^{\circ}$ 192, Serie 2. Seguido por Sociedad Unión de Labor Nacionalista sobre monumento a José Olaya. 1917.

Arosemena Garland, Geraldo, El monumento a la Gloria de Ayacucho, Lima, Talleres tipografía y offset peruana, 1974.

Basadre, Jorge, Perú Independiente, Lima, Empresa Editora El Comercio SA, 2010.

77 "Bisnieto de Olaya pide se erija monumento al mártir" (Lima, 1964, 1 de julio): 3. 
Bassi Cendra, Giovana María y Zavala Pflucker, Sandra Lucía. "Evolución y desaparición de la Alameda de Acho". En Concurso Juan Gunther. Investigaciones históricas sobre Lima, Lima. Municipalidad Metropolitana de Lima, 2014: 129-162.

"Bisnieto de Olaya pide se erija monumento al mártir", El Comercio (Lima, 1964, 1 de julio): 3 .

Burga, Manuel y Flores Galindo, Alberto, Apogeo y crisis de la república aristocrática, Lima, Ediciones Rikchay Perú, 1981.

Castrillón, Alfonso. "Escultura monumental y funeraria en Lima". En Escultura en el Perú, José Antonio de Lavalle Vargas (ed.), Lima, Banco de Crédito, 1991: 325-385.

Crousse Rastelli, Jean Pierre e Yrigoyen Arciniega, Elena. Chorrillos: Historia de un patrimonio. Clasificación-Reglamentación, Lima, s/f.

Denegri Luna, Felix, Historia Marítima del Perú. Época de la República, Tomo VI, Volumen 2, Lima, Instituto de Estudios Históricos Marítimos del Perú, 1981.

Diez Canseco, Pedro, "Decreto reestableciendo las cosas al Estado que se encontraban el 27 de noviembre de 1865", Congreso de la República del Perú, Arequipa, 1867a, 14 de octubre. Accesible en http://www4.congreso.gob.pe/museo/mensajes/ a-Mensaje-1867-8.pdf [Consulta 10 de abril de 2017].

Diez Canseco, Pedro, "Disponiendo levantar en la Alameda de los Descalzos una estatua al libertador Ramón Castilla". Leyes no numeradas desde el año 1820 al año 1904. Archivo digital de la legislación en el Perú. Congreso de la República del Perú, Arequipa, 1867b, 3 de noviembre. Accesible en http://www.leyes.congreso. gob.pe/Documentos/LeyesXIX/1867131.pdf [Consulta 10 de abril de 2017].

"El estandarte de Pizarro se guarda actualmente en el Municipio de Caracas" El Comercio (Lima, 1960, 19 de agosto): 3.

"El centenario de Olaya", Mundial, 164 (Lima, 1923, 6 de julio): s/p.

"El sacrificio del chorrillano Olaya". Mundial, 163 (Lima, 1923, 29 de junio): s/p.

El siglo XX de El Comercio. 1920-1929, Lima, El Comercio, Plaza Janés SA, 2000.

"En homenaje a José Olaya", Variedades, 801 (Lima, 1923, 7 de junio): s/p.

"Esta noche inician las actuaciones conmemorativas del 129 aniversario del sacrificio de José Olaya", El Comercio (Lima, 1952, 28 de junio): 7.

Gamarra Puertas, José Antonio, Historia y odisea de monumentos escultóricos conmemorativos, Lima, 1974.

Gamarra Puertas, José Antonio, Obras de arte y turismo monumental. Bronces ecuestres-estatuas (de pie y sentadas). Bustos y obeliscos, Lima, Imprenta Ku EIRL, 1996.

Gosselman, Carl August, "La República Peruboliviana”, Alberto Tauro del Pino (ed.), Viajeros del Perú Republicano, Lima, Universidad Mayor de San Marcos, 1967 [1837]: 47-69. 
Gutiérrez Viñuales, Rodrigo. Monumento conmemorativo y espacio público en Iberoamérica. Madrid, Ediciones Cátedra. Grupo Anaya, 2004.

Gutiérrez Viñuales, Rodrigo y Gutiérrez, Ramón. Pintura, escultura y fotografía en Iberoamérica, siglos XIX y XX, Madrid, Ediciones Cátedra, 1997.

"Hoy serán inaugurados los monumentos al general Miguel Iglesias y al mártir José Olaya", El Comercio (Lima, 29 de junio 1952): 3.

"Lima. Inauguración de la estatua de Colón”, El Comercio (Lima, 1860, 4 de agosto): $\mathrm{s} / \mathrm{p}$.

“La demolición de Petateros", Variedades, 180 (Lima, 1911, 12 de agosto): 978.

Leonardini Herane, Nanda. Los italianos y su influencia en la cultura artística peruana en el siglo XIX. Tesis para optar el grado de Doctora en Historia. Universidad Nacional Autónoma de México, Facultad de Filosofía y Letras, División de Estudios de Posgrado, México, 1998.

"Las ceremonias y actuaciones conmemorativas del 129 aniversario del sacrificio de José Olaya en Chorrillos", El Comercio (Lima, 1952, 29 de junio): 3.

"Las fiestas en homenaje al patriota José Olaya”, Mundial, 164 (Lima, 1923, 6 de julio): s/p.

"Las grandes efemérides nacionales. Centenario del martirio y muerte de José Olaya-junio de 1823”, Variedades, 800 (Lima, 1923, 30 de junio): s/p.

Majluf, Natalia, Escultura y espacio público. Lima, 1850-1879, Lima, Instituto de Estudios Peruanos, 1994.

Majluf, Natalia (ed.), José Gil de Castro. Pintor de libertadores, Lima, MALI, Museo Histórico Nacional, Museo Nacional Bellas Artes, Dirección de Bibliotecas, Archivos y Museos, Biblioteca del Perú, Colección Bicentenario, 2014.

Majluf, Natalia y Wuffarden, Luis Eduardo, La piedra de Huamanga, lo sagrado y lo profano, Lima, Museo de Arte de Lima, Banco de Crédito del Perú, Prom Perú, 1998.

Majluf, Natalia y Wuffarden, Luis Eduardo, "El siglo XIX: entre tradición y modernidad”, Natalia Majluf (ed.), Arte republicano, Lima, Sura. Asociación Museo de Arte de Lima, Mali, 2015: 1-59.

Mejía Ticona, Víctor, Prefiguración de la plaza San Martín y su monumento (18991921), Tesis para optar el título de Magister en historia del arte, Lima, Pontificia Universidad Católica del Perú, 2013.

Millones, Iván, "El mariscal Cáceres: ¿un héroe militar o popular? Reflexiones sobre un héroe patrio peruano", Iconos, revista de ciencias sociales, 26, (Quito, 2006): pp. 47-57.

Mondoñedo, Patricia, José Olaya: la obra disímil en la producción pictórica de José Gil de Castro, Lima, Tesis para optar el grado de licenciado en arte. Escuela de 
Arte, Facultad de Letras y Ciencias Humanas, Universidad Nacional Mayor de San Marcos, 2002.

Monteverde Sotil, Rodolfo, "Proyectos estatales para erigir un monumento público a José de San Martín (Lima 1822-1921)". Hacia el Bicentenario: 200 años de vida republicana (2010-2024). Revista electrónica del Vicerrectorado de Investigación de la Universidad Nacional Mayor de San Marcos, 1, (Lima, 2010): 41-59.

Monteverde Sotil, Rodolfo, "Proyectos estatales para erigir un monumento público al Día de la Independencia y al general José de San Martín en la ciudad de Lima durante el protectorado (1821-1822)", Concurso Juan Gunther. Investigaciones históricas sobre Lima, Lima, Gerencia Cultural de la Municipalidad Metropolitana de Lima, 2014a: 239-248.

Monteverde Sotil, Rodolfo, Proyectos estatales y privados para erigir un monumento público al general José de San Martín en Lima y el Callao (1822-1921), Lima, Tesis para optar el grado de licenciado en arte. Escuela de Arte, Facultad de Letras y Ciencias Humanas, Universidad Nacional Mayor de San Marcos, 2014b.

Monteverde Sotil, Rodolfo, "El Proyecto estatal de 1904 y su polémico concurso para erigir un monumento público al general José de San Martín en Lima”. Arkinka. Revista de Arquitectura, diseño y construcción, 218, (Lima, 2014c): 92-104.

Monteverde Sotil, Rodolfo, "El proyecto estatal para erigir un monumento público del general José de San Martín (Lima 1904-1921)", Alex Loayza Pérez (ed.), La independencia peruana como representación. Historiografía, conmemoración y escultura pública, Lima, Instituto de Estudios Peruano, 2016: 313-352.

Monteverde Sotil, Rodolfo, "Política internacional de la posguerra del Pacífico, remodelación urbana y proyectos escultóricos de Lima: el monumento público a Francisco Bolognesi y los caídos en la Batalla de Arica", Historia, 50/ II (Santiago de Chile, 2017): 663-697.

Monteverde Sotil, Rodolfo, "El monumento al Combate del 2 de Mayo en Lima: un símbolo americanista frente a España, 1866-1874", Procesos. Revista Ecuatoriana de Historia (Quito, 2019a): 39-75.

Monteverde Sotil, Rodolfo, Entre la posguerra con Chile y el plebiscito para recuperar a "Las Cautivas": espacio urbano y escultura pública dedicados a los próceres y héroes de la Patria, Lima 1883-1929. Tesis para optar el grado de magíster en historia del arte peruano y latinoamericano. Unidad de Posgrado de la Facultad de Letras y Ciencias Humanas, Universidad Nacional Mayor de San Marcos, 2019b.

Noriega, Zenón. Sobre reemplazo del monumento al coronel Francisco Bolognesi. Lima, 15 de junio. Concejo Provincial de Lima. Sección Archivo y Mesa de Parte, Casilla $\mathrm{N}^{\circ} 33$, Letra M, No 2251, Folio 376, Serie 1, Semestre 1. Lima, Archivo de la Municipalidad de Lima Metropolitana, 1951. 
Odriozola, Manuel, Documentos históricos del Perú. Colectados y arreglados por el coronel de caballería de ejército, fundador de la independencia Manuel Odriozola, Lima, Imprenta del Estado, 1873, Tomo IV y V.

Oviedo, Juan, Colección de leyes, decretos y órdenes publicadas en el Perú desde el año de 1821 hasta 31 de diciembre de 1859, Felipe Bailley (ed.), Lima, Ministerio de Gobierno, Culto y Obras Públicas, Librería Central Portal de Botoneros, 1861.

Palma, Ricardo, "José Olaya". La Revista de Buenos Aires. Historia Americana, literatura, derecho y variedades. Periódico dedicado a la República Argentina, la Oriental del Uruguay y la del Paraguay, XIV (Buenos Aires, 1867), Biblioteca de la Universidad de Texas. Accesible en https://books.google.com.pe/books?id=1_svAAAAYAAJ\&pg $=$ PA101\&lpg $=$ PA101\&dq=busto + de + olaya + en + chorrillos\&source $=$ bl\&ots $=$ Y $5 \mathrm{zBmzZ}$ VA5\&sig=LZT-iqEfiA0u8-R744HccTH1uDk\&hl=en\&sa=X\&ved=0ahUKEwic17mP mYjQAhUN1mMKHRxPAVcQ6AEIHTAA\#v=onepage\&q\&f=false [Consulta 1 de noviembre de 2016].

Quiroz, Alfonso, Historia de la corrupción en el Perú, Lima, Instituto de Estudios Peruanos, 2013.

Ramón Joffré, Gabriel, El Neoperuano. Arqueología, estilo nacional y paisaje urbano en Lima, 1910-1940, Lima, Sequilao Editores, 2014.

"Romería al monumento Olaya en Chorrillos", Variedades, 702 (Lima, 1921, 13 de agosto): 1137.

San Cristóval, Evaristo. Grandeza y esplendor de Chorrillos, Lima, Instituto Chorrillano de Medios de Comunicación y Archivos, 1999.

Tauro del Pino, Alberto, Enciclopedia Ilustrada del Perú, Lima, Editorial Peisa, XVII tomos, 2001.

Tristán, Flora, Peregrinaciones de una paria 1833-1834, Lima, Colección Tiempo, Moncloa Campodónico Editores Asociados, 1971.

Vifian, Daniel, "El civismo sobre las armas. La estatua de Simón Bolívar en Lima, 1825-1859", Alex Loayza Pérez (ed.), La Independencia peruana como representación. Historiografia, conmemoración y escultura pública, Lima, Instituto de Estudios Peruanos, 2016: 289-312.

Villegas Torres, Fernando. "La escultura en el 900: entre la obra europea importada y la formación de la escuela nacional". Revista del Museo Nacional, Tomo L. Lima, Ministerio de Cultura, 2010: 211-245.

Fecha de recepción: 16 de enero de 2018.

Fecha de envío de las modificaciones: 9 de marzo de 2018.

Fecha de aceptación: 21 de agosto de 2018. 


\section{State commemoration and sculptural representation of the hero of the Peruvian Independence Jose Olaya (1823-1953)}

The Peruvian hero Jose Olaya was an Indian fisherman of modest social status, differentiating himself from other Creole foreigners, military and economic situations peace, which led the Peruvian Independence as José de San Martín and Simon Bolivar. From 1823, when Olaya was shot by the Spaniards, near the Plaza Mayor of Lima, until 130 years after his death, the State first tried to pay homage to him with a canvas (1823) and then sporadically with a public monument (in 1867, 1923, and 1952). This text analyzes the social and political context in which these sculptures were proposed and inaugurated, what happened to them and how Olaya was represented.

KeY words: Jose Olaya; Independence; hero; public sculpture; Lima. 